1 Evolution of copper resistance in the kiwifruit pathogen Pseudomonas syringae pv. actinidiae through acquisition of integrative conjugative elements and plasmids

4

5 Elena Colombi ${ }^{1}$, Christina Straub ${ }^{1}$, Sven Künzel ${ }^{2}$, Matthew D. Templeton ${ }^{3,4}$,

6 Honour C. McCann ${ }^{1,5^{*}}$, Paul B. Rainey ${ }^{1,2,6^{*}}$

$8{ }^{1}$ New Zealand Institute for Advanced Study, Massey University, Auckland, New

9 Zealand. ${ }^{2}$ Max Planck Institute for Evolutionary Biology, Plön, Germany. ${ }^{3}$ Plant

10 and Food Research, Auckland, New Zealand. ${ }^{4}$ School of Biological Sciences,

11 University of Auckland, Auckland, New Zealand. ${ }^{5}$ South China Botanical Institute,

12 Chinese Academy of Sciences, Guangzhou, China. ${ }^{6}$ Ecole Supérieure de Physique

13 et de Chimie Industrielles de la Ville de Paris (ESPCI Paris-Tech), PSL Research

14 University, Paris, France. * Joint senior authors

15

16 Correspondence: Elena Colombi, New Zealand Institute for Advanced Study,

17 Massey University, Private Bag 102 904, Auckland 0745, New Zealand.

18 Telephone: +6494140800 ext 43810. e-mail: e.colombi@massey.ac.nz

20 Running title: Evolution of copper resistance

\title{
ORIGINALITY-SIGNIFICANT STATEMENT
}

23 Lateral gene transfer is a major evolutionary force, but its immediacy is often

24 overlooked. Between 2008 and 2010 a single virulent clone of the kiwifruit

25 pathogen Pseudomonas syringae pv. actinidiae spread to kiwifruit growing 
regions of the world. After arrival in New Zealand it acquired genetic

determinants of copper resistance in the form of integrative conjugative

elements and plasmids. Components of these elements are evident in distantly related bacteria from millet (USA, 1921), kiwifruit (Japan, 1988) and wheat (New

Zealand, 1968). Additional laboratory experiments capture evidence of the dynamism underpinning the evolution of these elements in real time and further emphasize the potent role that lateral gene transfer plays in microbial evolution.

\section{SUMMARY}

Lateral gene transfer can precipitate rapid evolutionary change. In 2010 the global pandemic of kiwifruit canker disease caused by Pseudomonas syringae pv. actinidiae ( $P s a$ ) reached New Zealand. At the time of introduction, the single clone responsible for the outbreak was sensitive to copper, however, analysis of a sample of isolates taken in 2015 and 2016 showed that a quarter were copper resistant. Genome sequences of seven strains showed that copper resistance comprising $c z c / c u s A B C$ and $\operatorname{cop} A B C D$ systems - along with resistance to arsenic and cadmium, was acquired via uptake of integrative conjugative elements (ICEs), but also plasmids. Comparative analysis showed ICEs to have a mosaic structure, with one being a tripartite arrangement of two different ICEs and a plasmid that were isolated in 1921 (USA), 1968 (NZ) and 1988 (Japan), from $P$. syringae pathogens of millet, wheat and kiwifruit, respectively. Two of the Psa ICEs were nearly identical to two ICEs isolated from kiwifruit leaf colonists prior to the introduction of Psa into NZ. Additionally, we show ICE transfer in vitro and in planta, analyze fitness consequences of ICE carriage, capture the de novo formation of novel recombinant ICEs, and explore ICE host-range. 
INTRODUCTION

Horizontal gene transfer (HGT) is a potent evolutionary process that significantly shapes patterns of diversity in bacterial populations. Horizontally transmissible elements, including plasmids, phages and integrative conjugative elements (ICEs) move genes over broad phylogenetic distances and mediate abrupt changes in niche preferences (Sullivan and Ronson, 1998; Ochman et al., 2000; Ochman et al., 2005; Guglielmini et al., 2011).

ICEs are plasmid-like entities with attributes of temperate phages that disseminate vertically as part of the bacterial chromosome and horizontally by virtue of endogenously encoded machinery for conjugative transfer (Wozniak and Waldor, 2010; Guglielmini et al., 2011). Essential genetic modules include those mediating integration, excision, conjugation and regulation of conjugative activity (Mohd-Zain et al., 2004; Juhas et al., 2007; Roberts and Mullany, 2009). During the process of conjugation ICEs circularize and transfer to new hosts, leaving a copy in the original host genome (Wozniak and Waldor, 2010; Johnson and Grossman, 2015). Conjugation during pathogenesis is often regulated by environmental signals (Lovell et al., 2009; Quiroz et al., 2011; Vanga et al., 2015). In addition to a set of essential genes, ICEs often harbour "cargo" genes of

70 adaptive significance to their hosts. These include genes affecting biofilm

71 formation, pathogenicity, antibiotic and heavy metal resistance, symbiosis and

72 bacteriocin synthesis (Peters et al., 1991; Rauch et al., 1992; Ravatn et al., 1998;

73 Beaber et al., 2002; Drenkard et al., 2002; Burrus et al., 2006; Ramsay et al., 74 2006; Dimopoulou et al., 2007; Kung et al., 2010). The genetic information stored 75 in cargo genes varies considerably causing ICEs to range in size from $20 \mathrm{~kb}$ to 
$500 \mathrm{~kb}$ (Johnson and Grossman, 2015).

In 2008 a distinct and particularly virulent form of the kiwifruit pathogen Pseudomonas syringae pv. actinidiae (Psa) was identified in Italy. It was subsequently disseminated throughout kiwifruit growing regions of the world causing a global pandemic that reached New Zealand (NZ) in 2010 (Balestra et al., 2010; Abelleira et al., 2011; Everett et al., 2011; Vanneste et al., 2011).

Genomic analysis showed that although the pandemic was derived from a single clone it acquired a set of distinctive ICEs during the course of its global journey (Mazzaglia et al., 2012; Butler et al., 2013; McCann et al., 2013). The NZ lineage carries $P s a_{\mathrm{NZ13}} \mathrm{ICE}$ _eno which harbours a $20 \mathrm{~kb}$ "enolase" region that is also found in otherwise divergent Psa ICEs (McCann et al., 2013; McCann et al., 2016). Copper sprays have long been used in NZ to protect plants from a range of diseases. Since the arrival Psa in NZ kiwifruit orchardists have employed copper based products to protect vines. From 2011 an ongoing industry-based programme has been in place to monitor copper resistance. In 2014 evidence was first obtained of Psa isolates resistant to copper sulphate. Given that the clone of Psa originally introduced into NZ was sensitive to copper and lacked genes encoding copper resistance (McCann et al., 2013), detection of copper resistance raised the possibility that the evolution of copper resistance in Psa is an evolutionary response to the use of copper-based sprays.

Here we report the phenotypic and genetic basis of copper resistance in NZ isolates of Psa and show that its emergence has been fuelled by lateral gene transfer involving ICEs and plasmids. We additionally describe the mosaic structure of ICEs, show the dynamics of ICE transfer both in vitro and in planta, 
100

101

102

103

104

105

106

107

108

109

110

111

112

113

114

115 ICE (Psa $a_{\mathrm{NZ13}}$ ICE_eno) at att-1 (immediately upstream of $\left.c l p B\right)$, is located at the

123

analyze fitness consequences of ICE carriage, capture the de novo formation of novel recombinant ICEs, and explore ICE host-range.

\section{RESULTS}

\section{Occurrence of copper resistance in Psa}

Psa NZ13, isolated in 2010 and representative of the clone introduced in New Zealand, lacks genes encoding copper resistance (McCann et al., 2013) and is unable to grow at copper concentrations in excess of $0.8 \mathrm{mM} \mathrm{CuSO}_{4}$. Prior to 2014 no copper resistant or tolerant strains had been reported. However, in 2014, two strains isolated from two different kiwifruit orchards, Psa NZ45 and Psa NZ47, displayed copper resistance, with a MIC of $1.2 \mathrm{mM} \mathrm{CuSO}_{4}$. This finding prompted a small-scale sampling of both copper treated and untreated orchards in 2015/2016 encompassing the area where resistance was first identified. From a sample of 213 strains isolated from seven orchards 59 were found to be copper resistant. Copper resistant isolates were sampled from both copper treated and untreated orchards. Additional copper resistant strains were procured from other kiwifruit-growing regions of New Zealand (Figure S1).

\section{ICE and plasmid-mediated acquisition of copper resistance in Psa}

The genome of the focal copper resistant isolate, Psa NZ45, is a direct clonal descendant of the isolate originally introduced into NZ (Psa NZ13) (McCann et al., 2016), but differs in two significant regards. Firstly, the "native" second att site (att-2) immediately downstream of queC (Figure 1). Secondly, the 
124 genome harbours a new $107 \mathrm{~kb}$ ICE $\left(P_{s} a_{\mathrm{NZ45}} \mathrm{ICE} \_\mathrm{Cu}\right)$ integrated at the $a t t-1$ site:

$125 P s a_{\mathrm{NZ45}} \mathrm{ICE} \_\mathrm{Cu}$ carries genes encoding copper resistance (Figures 1 and 2A).

126 The genomes of six additional copper resistant Psa isolates were also

127 sequenced (Table 1) and as with Psa NZ45, reads were aligned against the Psa

128 NZ13 reference genome (McCann et al., 2013; Templeton et al., 2015). All six

129 harbour mobile elements carrying genes encoding copper resistance. The

130 diversity of these elements and genomic location is shown in Figure 1 and their

131 structure is represented in Figure 2A. All isolates are direct clonal descendants of

132 Psa NZ13 and thus share an almost identical genome with the exception of the

133 determinants of copper resistance. In Psa NZ47 the genes encoding copper

134 resistance are located on a $90 \mathrm{~kb}$ ICE $\left(P s a_{\mathrm{NZ4} 4} \mathrm{ICE} \_\mathrm{Cu}\right)$ integrated at the att-1 site:

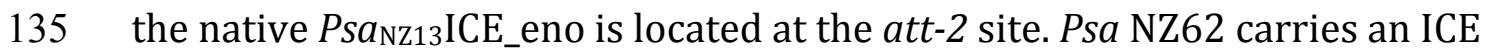

136 identical to that found in $P s a_{\text {NZ47 }} \mathrm{ICE} \_\mathrm{Cu}\left(\mathrm{Ps}_{\mathrm{NZ62}} \mathrm{ICE} \_\mathrm{Cu}\right)$, but is integrated at the

137 att-2 site; the native ICE ( $P_{s a_{\mathrm{NZ} 13}}$ ICE_eno) is absent leaving the att-1 site

138 unoccupied. Isolate Psa NZ63 carries $P s a_{\mathrm{NZ45}} \mathrm{ICE}$ _Cu integrated at the att-1 site,

139 but as in Psa NZ62, the native Psa ${ }_{\mathrm{NZ13}} \mathrm{ICE}_{-}$eno has been lost. Copper resistance

140 genes in isolate Psa NZ64 are also ICE-encoded, but the NZ64 ICE

141 (Psa $\left.{ }_{\text {NZ64 }} \mathrm{ICE} \_\mathrm{Cu}\right)$ is genetically distinct from both $P s a_{\mathrm{NZ47}} \mathrm{ICE} \_\mathrm{Cu}$ and

$142 P s a_{\mathrm{NZ45}} \mathrm{ICE} \_\mathrm{Cu}-$ at $130 \mathrm{~kb}$, it is also the largest. In NZ64, Psa ${ }_{\mathrm{NZ64}} \mathrm{ICE} \_\mathrm{Cu}$ is located

143 at the $a t t-1$ site and the $a t t-2$ site contains the native (Psa ${ }_{\text {NZ13 }}$ ICE_eno) ICE.

144 Isolates Psa NZ65 and NZ66 both harbour copper resistance genes on a near

145 identical, $120 \mathrm{~kb}$ previously undescribed plasmid (pPsaNZ65 and pPsaNZ66,

146 respectively). The only significant difference among the plasmids is the location

147 of a strepomycin resistance-encoding transposon (see below): both isolates have

148 the original $P s a_{\mathrm{NZ13}} \mathrm{ICE}$ _eno integrated at the $a t t-2$ site (Figure 1). Psa harbouring 
copper reistance-encoding ICEs have a MIC $\mathrm{CuSO}_{4}$ of $1.2 \mathrm{mM}$ while the MIC of plasmid-carrying Psa $1.5 \mathrm{mM}$ (Table 1).

That such a small sample of isolates is each unique with regard to the copper resistance-encoding element points to highly dynamic processes shaping their evolution. Such dynamism has been previously noted among enolaseencoding ICEs obtained from a global collection of epidemic Psa isolates (McCann et al., 2013) and has been observed elsewhere (Burrus et al., 2006, Wozniak and Waldorf, 2010). In this study our samples came from a relatively small geographical location. Two ICEs, $P s a_{\text {NZ64 }}$ ICE_Cu and $P s a_{\text {NZ47 }}$ ICE_Cu were found in different isolates sampled from the same orchard (one year apart), although the two isolates containing near identical plasmids were isolated from orchards located $100 \mathrm{~km}$ apart. Two isolates sampled one year apart from the same location (neighboring orchards in Te Puke) carry the same ICE $\left(P s a_{\mathrm{NZ45}} \mathrm{ICE}+\mathrm{Cu}=P s a_{\mathrm{NZ63}} \mathrm{ICE} \_\mathrm{Cu} ; P s a_{\mathrm{NZ47}} \mathrm{ICE} \_\mathrm{Cu}=P s a_{\mathrm{NZ62}} \mathrm{ICE}+\mathrm{Cu}\right)($ Table 1$)$. The dynamics of ICE evolution becomes especially evident when placed in the broader context possible by comparisons to ICEs recorded in DNA databases. The core genes of the copper resistance-encoding ICEs from New Zealand Psa isolates are syntenous with the core genes of the family of ICEs that includes PPHGI-1 (isolated in 1984 from bean in Ethiopia (Teverson, 1991; Pitman et al., 2005) and the three ICEs previously described from Psa found in New Zealand (2010), Italy (2008) and China (2010) (McCann et al., 2013; Butler et al., 2013; E. Colombi, unpublished). $P s a_{\mathrm{NZ} 45} \mathrm{ICE} \_\mathrm{Cu}$ is a mosaic of DNA from two known ICEs and a plasmid. It shares regions of near perfect identity (over $66 \mathrm{~kb}$ ) with ICEs present in the otherwise divergent host genomes of P. syringae pv. panici (Ppa, LGM2367) isolated from proso millet in Madison (USA) in the 1920s (over the 
174 first $38 \mathrm{~kb}$ it differs by just 12 SNPs, and one $144 \mathrm{bp}$ insertion), P. syringae pv.

175 atrofasciens (Paf, ICMP4394) isolated in NZ in 1968 from wheat, and a $70.5 \mathrm{~kb}$

176 plasmid present in a non-pandemic Psa strain (J2), isolated in Japan in 1988

177 (Figure 2B).

178 Interestingly, two of the ICEs described here have also been found in non-

179 Psa Pseudomonas isolated from kiwifruit leaves. Psa $a_{\mathrm{NZ47}} \mathrm{ICE}_{-} \mathrm{Cu}$ shows $99.7 \%$

180 pairwise nucleotide identity with an ICE found in P. marginalis ICMP 11289

181 isolated in 1991 from $A$. deliciosa in Katikati (New Zealand). Psa ${ }_{\text {NZ64 }} \mathrm{ICE}_{-} \mathrm{Cu}$ is

182 almost identical (99.5\% nucleotide pairwise identity) to an ICE from P. syringae

183 pv. actinidifoliorum (Pfm) ICMP19497, isolated from kiwifruit in 2010 in Te Puke

184 (New Zealand) (Visnovsky et al., 2016) (Table 1). Additionally, a 48 kb segment

185 of coding copper resistance genes $P_{s} a_{\text {NZ64 }} I C E \_C u$ shares $99.3 \%$ nucleotide

186 pairwise identity with a locus found in P. azotoformans strain S4 (Fang et al.,

187 2016), which was isolated from soil in 2014 in Lijiang (China). However, the

188 locus from P. azotoformans is not associated with an ICE.

\section{Genetic determinants of copper resistance}

191 Copper resistance is typically conferred by operons encoding either

192 copper efflux (cusABC) and / or sequestration (copABCD) systems, both of which

193 can be under the regulation of the copRS / cusRS two-component regulatory

194 system (Bondarczuk and Piotrowska-Seget, 2013). ICEs identified in Psa isolates

195 harbour operons encoding examples of both resistance mechanisms (and

196 regulators), plus genetic determinants of resistance to other metal ions. In each

197 instance the resistance genes are located within "variable regions" (VR) of ICEs

198 into which cargo genes preferentially integrate (Figure 2A). Delineation of these 
variable regions comes from detailed analysis of 32 unique ICEs from the Pph 1302A and Psa families that will be published elsewhere (E. Colombi, unpublished). Overall there are notable similarities and differences in the organization of the variable regions.

As shown in Figure 2B, the first $38 \mathrm{~kb}$ of $P s a_{\mathrm{NZ45}} \mathrm{ICE} \_\mathrm{Cu}$ is almost identical (99.7\% identical at the nucleotide level) to $P p a_{\mathrm{LGM} 2367}$ ICE. This region spans the core genes, but extends $\sim 8.2 \mathrm{~kb}$ into the variable cargo genes with just two SNPs distinguishing the two ICEs (across the $8.2 \mathrm{~kb}$ variable region). Encoded within this region is an integrase, arsenic resistance genes ( $\operatorname{ars} R B C H)$, a gene implicated in cadmium and cobalt resistance $(c z c D)$ and the copRS regulatory system.

Partway through copS the two ICEs diverge at a recombination breakpoint with the downstream variable region from $P s a_{\mathrm{NZ45}}$ ICE_Cu being homologous to a set of copper resistance genes found on plasmid pPaCu1 from the divergent (nonpandemic) Japanese isolate of Psa (J2) (Nakajima et al., 2002). This region comprises a putative copper transporting ATPase encoded by copG (GutiérrezBarranquero et al., 2013), cusABC genes involved in the detoxification of monovalent cations, including copper and silver (Mergeay et al., 2003; Rensing and Grass, 2003) and copABCD (Figure 2B). The last $4 \mathrm{~kb}$ of the variable region of

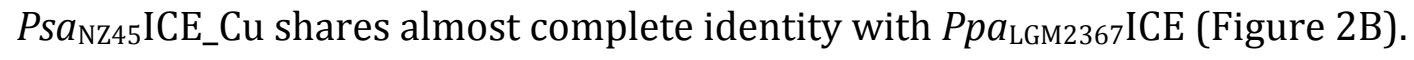
Detail of the diversity of copper resistance (and related metal resistance) genes is shown in Figure 3. All elements (ICEs and plasmids) harbour the copRS regulatory system and, with the exception of $P s a_{\mathrm{NZ47}} \mathrm{ICE} \mathrm{Cu}$, all carry both $\mathrm{cus} A B C$ and $\operatorname{cop} A B C D$, although their organization varies. For example, while $\operatorname{cop} A B C D$ is typical, in $P s a_{\mathrm{NZ64}} \mathrm{ICE} \_\mathrm{Cu} \operatorname{cop} A B$ and $\operatorname{cop} C D$ are organized as two separate operons (Figure 3). The putative copper ABC transport system encoded by copG 
224 is a common feature, and determinants of arsenic resistance are present in both

$225 P s a_{\text {NZ45 }}$ ICE_Cu and $P s a_{\text {NZ64 }}$ ICE_Cu. The putative cadmium and related metal

226 resistance gene, $c z c D$ is also present on these two ICEs. As noted above, a

227 transposon carrying determinants of streptomycin resistance (strAB) is present

228 on plasmids pPsaNZ65 and pPsaNZ66. The transposon is of the Tn3 family and

229 the cassette bears identity to streptomycin resistance carrying transposons

230 found in P. syringae pv. syringae B728a (Feil et al., 2005), but also on plasmid

231 pMRVIM0713 from Pseudomonas aeruginosa strain MRSN17623 (GenBank:

232 KP975076.1), plasmid pPMK1-C from Klebsiella pneumoniae strain PMK1

233 (Stoesser et al., 2014), and plasmid pTi carried by Agrobacterium tumefaciens

234 LBA4213 (Ach5) (GenBank: CP007228.1).

At the level of the operons determining copper resistance there is marked

236 genetic diversity, however, with the exception of CopR, there is relatively little

237 evidence of within operon recombination. The CusABC system is carried on

238 pPsaNZ65 and pPsaNZ66 (but these are identical) and the ICEs $P_{s} a_{\text {NZ45 ICE_Cu }}$

239 and $P s a_{\text {NZ64 }}$ ICE_Cu: CusA, CusB and CusC show 75.8\%, 50.0\% and 44.8\% pairwise

240 amino acid identity, respectively; phylogenetic trees based on protein sequences

241 show congruence (Figure S2). The CopABCD system is present on $P_{s} a_{\text {NZ45 ICE_Cu, }}$

$242 P s a_{\text {NZ47 }} \mathrm{ICE} \_\mathrm{Cu}, P s a_{\mathrm{NZ64}} \mathrm{ICE} \_\mathrm{Cu}$ (but CopAB and CopCD are in different locations

243 (Figure 3)) and plasmid pPsaNZ65 (and pPsaNZ66): CopA, CopB, CopC and CopD

244 show $76.4 \%, 63.1 \%, 79.1 \%$ and $60.8 \%$ pairwise amino acid identity,

245 respectively. With the exception of CopC (where bootstrap support is low)

246 phylogenetic trees for each protein show the same overall arrangement (Figure

247 S3). The two component regulatory system copRS is also present on each of the

248 elements with the amino acid sequences of CopR showing $84.3 \%$ and those of 
249 CopS 63.0\% pairwise amino acid identity. Phylogenetic trees show CopS from

$250 P s a_{\text {NZ64 }}$ ICE_Cu to be the most divergent, and those from $P s a_{\text {NZ45 }} I C E \_C u$ and

$251 P s a_{\text {NZ47 }}$ ICE_Cu being most similar: CopR shows the same phylogenetic

252 arrangement, however, CopR sequences from $P s a_{\text {NZ45 }} \mathrm{ICE} C \mathrm{Cu}$ and $P s a_{\mathrm{NZ} 47} \mathrm{ICE} C \mathrm{Cu}$

253 are identical at the protein level suggesting a recent recombination event (Figure 254 S4).

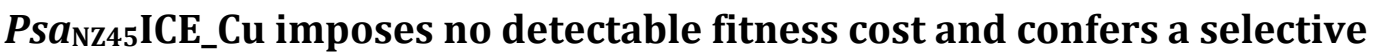

advantage in vitro in the presence of copper

To determine whether ICE carriage confers a fitness cost, we took

259 advantage of the fact that Psa NZ13 and Psa NZ45 are essentially isogenic, with

260 the exception of the additional ICE in Psa NZ45 (Psa $\left.{ }_{\mathrm{NZ45}} \mathrm{ICE}_{-} \mathrm{Cu}\right)$. Each strain was

261 grown alone and density of cells monitored over a 72 hour period with samples

262 taken every 24 hours. In the absence of copper sulphate, no difference in cell

263 density was detected; however, in the presence of 0.5 and $0.8 \mathrm{mM} \mathrm{CuSO}_{4}$ the

264 density of Psa NZ13 was reduced (Figure 4A). There is thus no apparent fitness

265 cost associated with carriage of $P s a_{\mathrm{NZ45}} \mathrm{ICE} \mathrm{ICu}_{-} \mathrm{Cu}$ the absence of copper sulphate,

266 but there is a fitness advantage in copper-containing environments.

267 Although carriage of $P s a_{\text {NZ45 }}$ ICE_Cu appeared not to affect the growth of

268 Psa NZ45 in the absence of copper, a more precise measure of fitness was sought

269 by performing competition experiments in which Psa NZ13 and Psa NZ45 were

270 co-cultured. For this experiment Psa NZ13 was marked with a kanamycin

271 resistance cassette so that it could be distinguished from kanamycin sensitive,

272 copper resistant Psa NZ45. Over a 24 hour period where the two strains

273 (founded at equal density) competed for the same resources (in shaken MGY 
medium without copper sulphate), the fitness of Psa NZ45 was not significantly different to $P s a$ NZ13 $(1.07 \pm 0.04$; mean and SEM from 3 independent experiments, each comprised of 3 replicates), indicating no significant detectable cost of carriage of $P s a_{\mathrm{NZ45}} \mathrm{ICE}+\mathrm{Cu}$.

Given that the mechanism of copper resistance in Psa NZ45 - based upon cop $A B C D$ - likely involves sequestration of copper ions we considered the possibility that this isolate might confer cross protection to non-copper resistant isolates, such as Psa NZ13. To this end we performed co-culture experiments at sub-inhibitory and inhibitory copper sulphate concentrations. Growth of Psa NZ13 at sub-inhibitory concentrations of copper sulphate was significantly impaired by the presence of Psa NZ45 and this was especially evident at 48 and 72 hours (Figure S5). At the inhibitory copper sulphate concentration, Psa NZ13 appeared to benefit from the presence of Psa NZ45. Again, this was most evident at 48 and 72 hours (Figure S5).

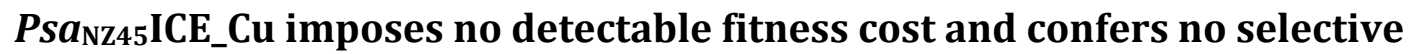
advantage in planta

Cost and benefit of carrying $P s a_{\mathrm{NZ45}} \mathrm{ICE} \_\mathrm{Cu}$ was also evaluated during endophytic colonization of kiwifruit leaves. No significant difference was observed in growth of singly-inoculated Psa NZ13 and NZ45 (dip inoculation was used to found colonization). Spray application of a commonly used commercial copper-based treatment (Nordox75 $\left(0.375 \mathrm{~g} \mathrm{~L}^{-1}\right)$ ) subsequent to dip inoculation resulted in a reduction of bacterial density of both strains and the presence of

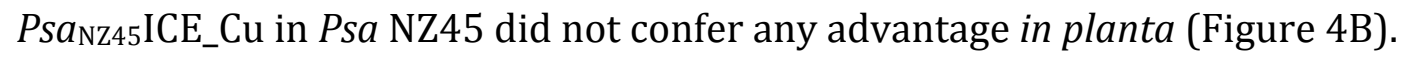
Co-cultivation competition assays in the presence or absence of Nordox75 
confirmed carriage of $P_{s} a_{\mathrm{NZ} 45} \mathrm{ICE}_{-} \mathrm{Cu}$ imposes no significant fitness cost or

300 advantage during endophytic growth: fitness of NZ45 relative to NZ13 was 1.00

$301 \pm 0.02$ and $1.07 \pm 0.03$ at day 3 and 7 , respectively; fitness of NZ45 relative to

302 NZ13 in the presence of $0.375 \mathrm{~g} \mathrm{~L}^{-1}$ Nordox was $1.15 \pm 0.04$ and $0.97 \pm 0.09$ at

303 day 3 and 7, respectively (data are means and SEM from 3 independent

304 experiments, each comprised of 5 replicates; significance was calculated by one 305 sample $t$-test).

306

\section{Psa $_{\mathrm{NZ45}} \mathrm{ICE}_{-} \mathrm{Cu}$ transfer dynamics in vitro and in planta}

Acquisition of $P s a_{\mathrm{NZ45}}$ ICE_Cu (and related ICEs) by Psa NZ13 suggests that

the element is active and capable of self-transmission. If so, then it is possible

that transfer may have occurred during the course of the co-cultivation

311 experiments used to determine cost of ICE carriage. To determine whether this

312 had happened samples from the mixtures were plated on MGY medium

313 containing both kanamycin and copper sulphate. Copper resistant, kanamycin

314 resistant transconjugants were detected both in vitro and in planta. This means

315 that a fraction of Psa NZ13 strains acquired Psa ${ }_{\text {NZ45 ICE_Cu. These }}$

316 transconjugants marginally inflate the counts of Psa NZ45, however, the number

317 of transconjugants (see below) was several orders of magnitude less that Psa

318 NZ13, thus having no appreciable effect on the measures of relative fitness.

319 At 24 hours in shaken MGY broth transconjugants were present at a

320 frequency of $5.04 \pm 2.25 \times 10^{-3}$ per recipient cell (mean and SEM from 3

321 independent experiments, each comprised of 3 replicates). Analysis of samples

322 from in planta experiments showed that at 3 days, transconjugants were present

323 at a frequency of $2.05 \pm 0.63 \times 10^{-2}$ per recipient cell (mean and SEM from 3 
independent experiments, each comprised of 5 replicates). On plants in the presence of Nordox $\left(0.375 \mathrm{~g} \mathrm{~L}^{-1}\right)$ the frequency of transconjugants was $9.37 \pm$ $1.56 \times 10^{-2}$ per recipient three days after inoculation (mean and SEM from 3 independent experiments, each comprised of 5 replicates). Transfer was also observed in M9 agar, on M9 agar supplemented with $0.5 \mathrm{mM} \mathrm{CuSO}_{4}$, on M9 agar supplemented with a macerate of Hort16A fruit with transconjugants present (at 48 hours) at a frequency of $2.16 \pm 0.9 \times 10^{-5}, 1.11 \pm 0.4 \times 10^{-5}$ and $1.98 \pm 0.8 \times 10^{-5}$ per recipient cell, respectively. To explore the dynamics of transfer in vitro, samples from shaken MGY cultures were taken hourly, for six hours, and then at 24 hours. The data, presented in Figure 5, show acquisition of $P_{s} a_{\mathrm{NZ45}} \mathrm{ICE}$ _Cu by $P s a$ NZ13 within one hour of the mating mix being established (approximately 1 recipient per $10^{5}$ recipient cells). The frequency was relatively invariant over the subsequent six hour period, but rose to approximately 1 recipient in $10^{3}$ cells at 24 hours. Detection of ICE transfer just one hour after mixing donor and recipient cells promoted a further experiment in which transconjugants were assayed at 10 minute intervals. From three independent experiments, each with five replicates, transconjugants were detected at 30 mins (approximately $4 \times 10^{-7}$ transconjugants per recipient cell).

Analysis of co-cultivation experiments from kiwifruit leaves showed evidence that $P s a_{\text {NZ45 }} \mathrm{ICE}$ _Cu also transferred in planta. The frequency of transconjugants at day 3 and day 7 was approximately 1 per 50 recipient cells and the frequency of transconjugants was not affected by changes in the initial founding ratios of donor and recipient cells (Table S1). Overall, the frequency of 
transconjugants was approximately three orders of magnitude greater in planta than in vitro.

\section{ICE displacement and recombination}

To check the genetic composition of transconjugants and to investigate whether $P s a_{\mathrm{NZ45}} \mathrm{ICE} \_\mathrm{Cu}$ integration in recipient cells occurred at the att-1 or att-2 site, a set of primers were designed to identify the location of ICE integration in the Psa NZ13 genome (Table S2). 11 independently generated transconjugants from shaken MGY culture were screened. As expected, successful amplification of primers annealing to $\operatorname{cop} A B C D$ in $P s a_{\mathrm{NZ45}} \mathrm{ICE}_{-} \mathrm{Cu}$ was observed in all transconjugants, while amplification of the enolase gene primers (indicative of the presence of the native Psa $a_{\mathrm{NZ13}}$ ICE_eno) occurred only in Psa NZ13 and Psa NZ45 (Figure S6). However, in two transconjugants only the IntPsaNZ13-att-1 primer pair resulted in amplification, suggesting that recombination between $P s a_{\mathrm{NZ45}} \mathrm{ICE} \_\mathrm{Cu}$ and $P s a_{\mathrm{NZ13}} \mathrm{ICE}$ _eno had occurred (Figure S7). Genome sequencing of one of these transconjugants revealed a recombination event inside the variable region of the ICE that produced a chimeric ICE identical to $P s a_{\mathrm{NZ} 45} \mathrm{ICE} \_\mathrm{Cu}$ up to and including the CuR operon, with the remainder identical to the downstream segment of $P s a_{\mathrm{NZ13}} \mathrm{ICE} \_$eno (Figure 6).

\section{$P s a_{\mathrm{NZ45}} \mathrm{ICE}$ _Cu can be transferred to a range of $P$. syringae strains}

The host range of the $P s a_{\mathrm{NZ45}} \mathrm{ICE} \_\mathrm{Cu}$ was characterised using a panel of nine different Pseudomonas strains as recipients, representing the diversity of $P$. syringae and the genus more broadly. Transfer of Psa ${ }_{\mathrm{NZ45}} \mathrm{ICE} \_\mathrm{Cu}$ to Psa J31, Pfm NZ9 and P. syringae pv. phaseolicola (Pph) 1448a (on M9 agar plates) was 
373 observed with the frequency of transconjugants per recipient cell being $7.64 \pm$

$3741.7 \times 10^{-6}, 7.74 . \pm 2.5 \times 10^{-7}$ and $1.23 \pm 0.2 \times 10^{-4}$, respectively. No transconjugants

375 were detected for P. aeruginosa PA01, P. fluorescens SBW25, P. syringae pv.

376 tomato DC3000 or Psa K28, despite the fact that these three strains have both att

377 sites.

\section{DISCUSSION}

The importance and impact of lateral gene transfer on the evolution of

381 microbial populations has long been recognized (Sullivan et al., 1995; Lilley and

382 Bailey, 1997; Ochman et al., 2000; Ochman et al., 2005; Wozniak and Waldor,

383 2010; Polz et al., 2013). Here we have captured the real time evolution of copper

384 resistance in a plant pathogen, in an agricultural setting, and shown that

385 movement of copper resistance genes occurs primarily via ICEs. The strains

386 subject to genomic analysis provide a glimpse of just how dynamic evolution

387 fuelled by ICEs can be. Of the seven copper resistant Psa isolates analyzed, five

388 contain copper resistance-encoding ICEs - three unique ICEs in total - with

389 variable placement within the Psa genome, including movement and instability

390 of the native ICE ( $P s a_{\mathrm{NZ13}}$ ICE_eno). Further evidence of dynamism comes from in

391 vitro and in planta studies, which show not only transfer to isogenic Psa and

392 unrelated P. syringae strains, but also the ready formation of chimeras between

$393 P s a_{\mathrm{NZ45}} \mathrm{ICE} \_\mathrm{Cu}$ and $P s a_{\mathrm{NZ13}} \mathrm{ICE}$ _eno. Mosaicism of ICEs has been reported

394 elsewhere and is often promoted by the presence of tandem copies (Garriss et al.,

395 2009; Wozniak and Waldor, 2010). The ease with which ICEs move between

396 strains and capacity for intra-ICE recombination emphasizes the futility of

397 drawing conclusions on strain phylogeny based on ICE phylogeny (McCann et al., 
2013), but also the impossibility of understanding ICE evolution based on the phylogeny of ICEs themselves.

Evidence of the formation of chimeric ICEs extends beyond the ICEs studied here. $P s a_{\mathrm{NZ45}} \mathrm{ICE} \_\mathrm{Cu}$ is a recombinant of two previously reported ICEs and a plasmid: most surprising is the fact that the recombinant components are derived from elements isolated from three geographic regions (USA, Japan and New Zealand) from three different plants (millet, kiwifruit and wheat) and spanning almost 100 years. Additionally, two of the copper resistance-encoding ICEs found in Psa (Psa $a_{\mathrm{NZ47}} \mathrm{ICE} \_\mathrm{Cu}$ and $\left.\mathrm{Psa}_{\mathrm{NZ64}} \mathrm{ICE} \_\mathrm{Cu}\right)$ have been reported in other kiwifruit leaf colonizing organisms emphasizing the ease by which selftransmissible elements can move between members of a single community. Clearly the potency of evolution fuelled by ICEs with the P. syringae complex is remarkable, with impacts likely extending well beyond that inferred from the analysis of genome sequences (Fondi et al., 2016).

Evidence of the spectrum and dynamic of transfer inferred from the genomic analysis of natural isolates is bolstered by demonstration of the in vitro and in planta transfer of $P s a_{\mathrm{NZ45}} \mathrm{ICE} \_\mathrm{Cu}$. The fact that $P s a_{\mathrm{NZ45}} \mathrm{ICE} \mathrm{ICu}_{-} \mathrm{can}$ be detected in a recipient strain just 30 minutes after mixing with a donor strain (in shaken broth culture) points to an as yet undetermined proficiency for transfer and possible regulatory mechanism. At the same time, the frequency of transconjugants in planta are several orders of magnitude greater than in vitro suggesting even greater potential (perhaps regulated) for transfer in the natural environment.

The selective causes underpinning the evolution of copper resistance in Psa is uncertain and to date copper resistance is not known to have evolved 
outside of New Zealand. While it is tempting to blame use of copper sprays by orchardists, it is possible that the evolution of copper resistant Psa is a more general response to copper levels in New Zealand soils combined with long-term use of copper-based sprays in New Zealand agriculture (Morgan and Taylor, 2004). Support for this stems from the fact that $P s a_{\text {NZ47 }} I C E \_C u$ shows almost perfect identify with an ICE found in P. marginalis (ICMP 11289) from kiwifruit isolated in 1991 (in New Zealand). In addition, copper resistance-encoding ICEs were found in both copper treated, and untreated orchards. There is need to understand further the population ecology of copper-resistance ICEs at regional, national and global scales and the selective causes for their maintenance and spread (Staehlin et al., 2016). The impact of the copper resistance-encoding ICEs on fitness in plantain the presence of copper sprays - appears to be minimal. While this is heartening news from the perspective of control of the pathogen, there are at least three reasons to treat this result with caution. Firstly, it is difficult to accurately assess fitness in planta and it is possible that our measures underestimate the contribution of copper resistance to growth in the presence of copper: even a $1 \%$ increase in fitness over 24 hours, which is beyond experimental capacity to detect, can have significant long-term consequences. Secondly, the presence of copper resistance genes means opportunity for levels of resistance to increase through, for example, promoter mutations that increase levels of transcription of resistance determinants, or through acquisition of additional copper resistance-encoding genes. Thirdly, and perhaps most significantly, is the fact that the copper resistance-encoding ICEs confer no measurable fitness cost even in the absence of copper. This suggests that these 
448 elements will not be readily lost from Psa populations even if copper-based

449 sprays were eliminated (Andersson and Hughes, 2010; Neale et al., 2016). That

450 some strains of the global pandemic now contain two ICEs gives reason to

451 suspect elevated evolutionary potential among these isolates.

While the focus of our investigation has been copper resistance, the ICEs

reported here carry a cargo of additional genes, some of which are implicated in

454 resistance to other metals. In some instances the cargo genes have no similarity

to genes of known function (grey boxes in Figure 2A). ICEs and similar laterally

transferred elements provide opportunity for genes unrelated to copper

resistance, for example gene connected to virulence, to hitchhike and rapidly

spread. In this regard the two plasmids characterized here are of interest: both

carry determinants of streptomycin resistance - an antibiotic that is also sprayed

hitchhiking has been previously noted in the context of antibiotic resistanceencoding plasmids (Gullberg et al., 2014).

464 microbial evolution extends less than twenty years (Wozniak and Waldor, 2010).

465 While it might be argued that this potential is no different from that long realized 466 via conjugative plasmids, or phage (Ochman et al., 2000), ICEs, being a composite

467 of both, seem to have an edge. Unlike conjugative plasmids that rarely integrate

468 into the host genome, ICEs integrate as a matter of course and are largely

469 immune to segregational loss; additionally, fitness consequences as a result of

470 carriage are likely to be minimal. Unlike temperate phages, ICEs do not kill the

471 host upon transfer, but they can nonetheless mediate transfer upon

472 encountering transfer proficient conditions. Having control over both vertical 
473

474

475

476

477

478

479

480

481

482

483

484

485

486

487

488

489

490

491

492

493

494

495

496

and horizontal modes of transmission, while minimizing costs for host cells, marks these elements as especially potent vehicles of microbial evolution.

\section{EXPERIMENTAL PROCEDURES}

\section{Strains and culture condition}

All Pseudomonas strains were cultured in King's B medium at $28^{\circ} \mathrm{C}$, E. coli was cultured in Luria Bertani medium at $37^{\circ} \mathrm{C}$. All liquid overnight cultures were shaken at $250 \mathrm{rpm}$. Both kanamycin and nitrofurantoin were used at $50 \mu \mathrm{g} \mathrm{mL}^{-1}$.

\section{DNA extraction and genome sequencing}

For genome sequencing, DNA samples were extracted using the Promega Wizard ${ }^{\circ}$ Genomic DNA Purification Kit following the recommended protocol. Psa NZ45 was sequenced using the PacBio platform, the remainder were sequenced using the Illumina HiSeq platform. Sequences are deposited at NCBI with the following accession numbers: XXXX1, XXXX2 etc (right number of accession numbers).

\section{Genomic reconstruction of ICEs}

ICEs identified in genome sequences were used as query sequences for BLAST searches of the NCBI WGS database (http://blast.ncbi.nlm.nih.gov/Blast.cgi). Contigs were subsequently downloaded and where ICEs were represented by two contigs they were concatenated in Geneious (http://www.geneious.com, Kearse et al., 2012). Concatenation was only required in two instances. ICEs were annotated using 
497

498

499

500

501

502

503

504

505

506

507

508

509

510

511

512

513

514

515

516

517

518

519

520

521

the RAST server (http://rast.nmpdr.org, Aziz et al., 2008) and manually curated. Alignments were performed using Geneious.

\section{Psa isolation from kiwifruit orchards}

One $\mathrm{cm}^{2}$ kiwifruit leaf disks were macerated in $200 \mu \mathrm{l} 10 \mathrm{mM} \mathrm{MgCl}_{2}$. The macerate was plated on Pseudomonas selective media amended with cetrimide, fucidin and cephalosporin (Oxoid) and incubated at $28^{\circ} \mathrm{C}$ for 3 days. Psa was identified using either diagnostic PCR or LAMP assays (Rees-George et al., 2010, Ruinelli et al., 2016).

\section{Copper resistance assays}

Copper resistance was evaluated by determining the minimal concentration of copper that inhibited growth (minimal inhibitory concentration, MIC) on mannitol-glutamate yeast extract medium (MGY) plates supplemented with $\mathrm{CuSO}_{4} \cdot 5 \mathrm{H}_{2} \mathrm{O}$ (Bender and Cooksey, 1986, Cha and Cooksey 1991). Psa strains were considered resistant when their MIC exceeded $0.8 \mathrm{mM}$ $\mathrm{CuSO}_{4}$

\section{Mutant development}

A Tn5 transposon was used to generate kanamycin resistant (kanR) strains. E. coli S17-1 Tn5hah Sgid1 (Zhang et al., 2015) was used as donor and E. coli pK2013 (Ditta et al., 1980) as helper. Helper, donor and recipients were grown overnight. $200 \mu \mathrm{l}$ of helper and donor and $2 \mathrm{~mL}$ of recipient were separately washed with $10 \mathrm{mM} \mathrm{MgCl}_{2}$ and then mixed together and washed again. The mix was then re-suspended in $30 \mu \mathrm{l}$ of $10 \mathrm{mM} \mathrm{MgCl}_{2}$, plated on pre- 
522

523

524 kanamycin nitrofurantoin plates. Selected mutants were screened for normal 525 growth in KB, LB and M9.

526

\section{In vitro growth}

warmed LB agar plates and incubated for $24-48$ hours at $28^{\circ} \mathrm{C}$. Cells were then harvested, resuspended in $1 \mathrm{ml}$ of sterile $10 \mathrm{mM} \mathrm{MgCl}_{2}$ and plated on $\mathrm{KB}$

\section{In vitro growth}

Overnight cultures of Psa NZ13 ${ }^{\mathrm{kanR}}$ and Psa NZ45 were used to determine the in vitro growth of each strain in MGY alone or supplemented with 0.5 and $0.8 \mathrm{mM} \mathrm{CuSO}_{4} .10 \mathrm{~mL}$ liquid MGY cultures were established with a starting density of $10^{5} \mathrm{cfu} \mathrm{mL^{-1 }}$ and shaken for up to three days. Bacterial growth was monitored by plating on KB kanamycin ( $\left.P s a \mathrm{NZ13}^{\mathrm{kanR}}\right), \mathrm{MGY}^{2} .8 \mathrm{mM} \mathrm{CuSO}_{4}(P s a$ NZ45). Three replicates per strain and media combination was used, and the experiment was repeated three times.

\section{In planta growth}

Clonally propagated Actinidia chinensis var. 'Hort16A' plantlets were maintained at $20^{\circ} \mathrm{C}$ with a light/dark period of $14 / 10$ hours, $70 \%$ constant humidity. Psa NZ13 ${ }^{\mathrm{kanR}}$ and Psa NZ45 were grown on KB agar plates for $48 \mathrm{~h}$ at $28^{\circ} \mathrm{C}$. Inoculum with a final optical density $\left(\mathrm{OD}_{600}\right)$ of 0.2 of either strain was prepared in $50 \mathrm{ml} 10 \mathrm{mM} \mathrm{MgCl}_{2}$ with $0.002 \%$ of Silwet. Three to four week old plantlets were inoculated by dipping the aerial parts in the inoculum solution for 5 seconds. Five separate plantlets were dip inoculated for each treatment. For experiments assessing in planta growth in copper-sprayed plantlets, Nordox75 was used at the recommended dosage of $0.375 \mathrm{~g} \mathrm{~L}^{-1}$.

(www.kvh.org.nz/spray_products). Dip-inoculated plantlets were allowed to dry, 
547 then sprayed adaxially and abaxially with Nordox75 until runoff to ensure

548 complete coverage. Bacterial growth was monitored 0,3 and 7 days post

549 inoculation. $1 \mathrm{~cm}^{2}$ disk leaves were cut using a sterile cork borer, surface

550 sterilized in $70 \%$ ethanol and ground in $200 \mu \mathrm{l} 10 \mathrm{mM} \mathrm{MgCl}_{2}$. Serial dilutions of

551 the homogenate were plated on KB kanamycin to count Psa NZ13 ${ }^{\mathrm{kanR}}$ and MGY

$552 \quad 0.8 \mathrm{mM} \mathrm{CuSO}_{4}$ to count Psa NZ45.Each experiment was repeated 3 times.

553

554

555

556

557

558

559

560

561

562

563

564

565

566

567

568

569

570

571

\section{In vitro and in planta competition assays}

In vitro and in planta competition assays were conducted as described earlier for single strains, except that Psa NZ45 and Psa NZ13 ${ }^{\mathrm{kanR}}$ were coinoculated in a 1:1 mix. Bacterial growth was monitored by plating serial dilutions on KB kanamycin (Psa NZ13 ${ }^{\mathrm{kanR}}$ ), MGY 0.8mM CuSO 4 (Psa NZ45) and on MGY kanamycin $0.8 \mathrm{mM} \mathrm{CuSO}_{4}\left(P s a \mathrm{NZ}{ }^{\mathrm{kanR}}\right.$ that acquired copper resistance). In vitro assays had three replicates per strain, in planta assays were conducted using five replicates, each experiment was repeated three times. Fitness was calculated as ratio between their Malthusian Parameters (Lenski et al., 1991).

\section{ICE integration screening}

Primers used in this study are listed in Supp Table 2. Four primers were designed to detect the genomic location of ICE integration: two specific for the integrases at the end of each ICEs (IntPsaNZ45, IntPsaNZ13) and two for the ICE insertion site on the chromosome, annealing to the $\operatorname{clpB}$ (att-1 site) and queC (att-2 site) genes. The primer combination (IntPsaNZ45-att-2, IntPsaNZ45-att-1, IntPsaNZ13-att-1, and IntPsaNZ13-att-2) indicates the location of the ICEs. Another two sets of primers were designed to amplify either $\operatorname{CuR}(\operatorname{cop} A)$ or 
572 enolase genes present in the VR of $P s a_{N Z 45} I C C_{-} C u$ and $P s a_{\text {NZ13 ICE_eno, }}$

573 respectively. PCRs were performed using Thermo Scientific Taq DNA Polymerase

574 following the manufacturer's instructions.

575

576

\section{ICE mobilization assay}

Psa NZ45 was used as the ICE donor. Strains tested in the mobilization assays included are listed in order of divergence relative to the donor: Psa K28

(biovar 2) (McCann et al., 2013), Psa J31 (biovar 1) (McCann et al., 2013), Peusomonas syringae pv. actinidifoliorum NZ9 (McCann et al., 2013), Pseudomonas syringae pv. tomato DC3000 (Buell et al., 2003), Pseudomonas syringae pv phaseolicola 1448a (Teverson, 1991), Pseudomonas syringae H24 and H33 (isolated from kiwifruit; C. Straub, unpublished data), Pseudomonas fluorescens SBW25 (Zhang et al., 2006) and Pseudomonas aeroginosa PA01 (Holloway, 1955). The copper sulphate MIC was determined for all tested recipient strains, which were all tagged with kanamycin Tn5. A biparental mating was performed using $2 \mathrm{~mL}$ and $200 \mu \mathrm{l}$ of washed recipient and Psa NZ45 cells, respectively. The cells were mixed, centrifuged briefly and resuspended in $30 \mu \mathrm{l}$ of $10 \mathrm{mM} \mathrm{MgCl}_{2}$ alone, $10 \mathrm{mM} \mathrm{MgCl}_{2}$ with $0.5 \mathrm{mM} \mathrm{CuSO}_{4}$ or $30 \mu \mathrm{l}$ of $1 \mathrm{~cm}^{2}$ kiwifruit plantlet macerate in $200 \mu \mathrm{l}$ of $10 \mathrm{mM} \mathrm{MgCl}_{2}$ if requested. The cell mixture was plated onto solid media (M9 plates) and incubated at $28^{\circ} \mathrm{C}$ for 48 hours. Cells were then harvested and resuspended in $1 \mathrm{ml}$ of sterile $10 \mathrm{mM} \mathrm{MgCl}$. Serial dilutions were plated on KB kanamycin to count the total number of recipients and on MGY amended with kanamycin and copper sulphate at recipient MIC to count transconjugants. 
597

598

599

600

601

602

603

604

605

606

607

608

609

610

611

612

613

614

615

616

617

618

619

620

621

\section{Biosecurity and approval}

All worked was performed in approved facilities and in accord with APP201675, APP201730, APP202231.

\section{ACKNOWLEDGMENTS}

We gratefully acknowledge Zespri International Limited and Te Puke Fruit

Growers Association for financial support. The sponsors had no role in the design, collation, or interpretation of data. We thank kiwifruit growers in $\mathrm{Te}$ Puke for the access to orchards, Denis Robinson for providing Nordox75, and Daniel Rexin for assistance with isolating Psa from kiwifruit leaves.

\section{REFERENCES}

Abelleira, A., López, M.M., Peñalver, J., Aguín, O., Mansilla, J.P., Picoaga, A. and García, M.J. (2011) First report of bacterial canker of kiwifruit caused by Pseudomonas syringae pv. actinidiae in Spain. Plant Dis 95: 1583.

Andersson, D.I. and Hughes, D. (2010) Antibiotic resistance and its cost: is it possible to reverse resistance? Nature Reviews Microbiology 8: 260-271.

Aziz, R.K., Bartels, D., Best, A.A., DeJongh, M., Disz, T., Edwards, R.A. et al. (2008)

The RAST Server: rapid annotations using subsystems technology. BMC Genomics 9: 75-10.1186/1471-2164-9-75.

Balestra, G.M., Renzi, M. and Mazzaglia, A. (2010) First report of bacterial canker of Actinidia deliciosa caused by Pseudomonas syringae pv. actinidiae in Portugal. New Dis Rep 22: 10.

Beaber, J.W., Hochhut, B. and Waldor, M.K. (2002) Genomic and functional analyses of SXT, an integrating antibiotic resistance gene transfer element 
623 Bender, C.L. and Cooksey, D.A. (1986) Indigenous plasmids in Pseudomonas

624 syringae pv. tomato: conjugative transfer and role in copper resistance. J.

$625 \quad$ Bacteriol 165: 534-541.

626 Bondarczuk, K. and Piotrowska-Seget, Z. (2013) Molecular basis of active copper

627 resistance mechanisms in Gram-negative bacteria. Cell Biol Toxicol 29: 397628405.

629 Buell, C.R., Joardar, V., Lindeberg, M., Selengut, J., Paulsen, I.T., Gwinn, M.L. et al.

630 (2003) The complete genome sequence of the Arabidopsis and tomato

631 pathogen Pseudomonas syringae pv. tomato DC3000. Proc Nat Acad Sci U S A

632 100: 10181-10186.

633 Burrus, V., Marrero, J. and Waldor, M.K. (2006) The current ICE age: biology and 634 evolution of SXT-related integrating conjugative elements. Plasmid 55: 173635183.

636 Butler, M.I., Stockwell, P.A., Black, M.A., Day, R.C., Lamont, I.L. and Poulter, R.T.M. 637 (2013) Pseudomonas syringae pv. actinidiae from recent outbreaks of kiwifruit 638 bacterial canker belong to different clones that originated in China. PLoS ONE 639 8: e57464.

640 Cha, J.S. and Cooksey, D.A. (1993) Copper hypersensitivity and uptake in 641 Pseudomonas syringae containing cloned components of the copper resistance 642 operon. Appl Environ Microbiol 59: 1671-1674.

643 Dimopoulou, I.D., Kartali, S.I., Harding, R.M., Peto, T.E.A. and Crook, D.W. (2007)

644 Diversity of antibiotic resistance integrative and conjugative elements among 645 haemophili. J Med Microbiol 56: 838-846.

646 Ditta, G., Stanfield, S., Corbin, D., Helinski, D.R. (1980) Broad host range DNA 
647 cloning system for gram-negative bacteria: construction of a gene bank of $648 \quad$ Rhizobium meliloti. Proc Natl Acad Sci U S A 77: 7347-7351.

649 Drenkard, E. and Ausubel, F.M. (2002) Pseudomonas biofilm formation and 650 antibiotic resistance are linked to phenotypic variation. Nature 416: 740-743. 651 Everett, K.R., Taylor, R.K., Romberg, M.K., Rees-George, J., Fullerton, R.A., 652 Vanneste, J.L. and Manning, M.A. (2011) First report of Pseudomonas syringae 653 pv. actinidiae causing kiwifruit bacterial canker in New Zealand. Australasian $654 \quad$ Plant Dis Note 6: 67-71.

655 Fang ,Y., Wu, L., Chen, G., Feng, G. (2016) Complete genome sequence of 656 Pseudomonas azotoformans S4, a potential biocontrol bacterium. J Biotechnol $657 \quad 227: 25-26$.

658 Feil, H., Feil, W.S., Chain, P., Larimer, F., Di Bartolo, G., Copeland, A., et al. (2005) 659 Comparison of the complete genome sequences of Pseudomonas syringae pv. 660 syringae B728a and pv. tomato DC3000. Proc Natl Acad Sci U S A 102: 11064661 11069.

662 Fondi, M., Karkman, A., Tamminen, M.V., Bosi, E., Virta, M., Fani, R. et al. (2016)

663 "Every gene is everywhere but the environment selects": global 664 geolocalization of gene sharing in environmental samples through network 665 analysis. Genome Biol Evol 8: 1388-1400.

666 Garriss, G., Waldor, M.K. and Burrus, V. (2009) Mobile antibiotic resistance 667 encoding elements promote their own diversity. PLoS Genetic 5: e1000775. 668 Guglielmini, J., Quintais, L., Garcillán-Barcia, M. P., de la Cruz, F., Rocha, E.P. 669 (2011) The repertoire of ICE in prokaryotes underscores the unity, diversity, 670 and ubiquity of conjugation. PLoS Genet 7: e1002222.

671 Gullberg, E., Albrecht, L.M., Karlsson, C., Sandegren, L. and Andersson, D.I. (2014) 
672 Selection of a multidrug resistance plasmid by sublethal levels of antibiotics 673 and heavy metals. mBio 5: e01918-14.

674 Gutiérrez-Barranquero, J.A., de Vicente, A., Carrión, V.J., Sundin, G.W. and Cazorla, 675 F.M. (2013) Recruitment and rearrangement of three different genetic 676 determinants into a conjugative plasmid increase copper resistance in 677 Pseudomonas syringae. Appl Environ Microbiol 79: 1028-1033.

678 Holloway, B.W. (1955) Genetic recombination in Pseudomonas aeruginosa. J Gen $679 \quad$ Microbiol 13: 572-581.

680 Johnson, C.M. and Grossman, A.D. (2015) Integrative and conjugative elements 681 (ICEs): what they do and how they work. Annu Rev Genet 49: 577-601. 682 Juhas, M., Power, P.M., Harding, R.M., Ferguson, D.J., Dimopoulou, I.D., Elamin, 683 A.R., et al. (2007) Sequence and functional analyses of Haemophilus spp. 684 genomic islands. Genome Biol 8: R237.

685 Kearse, M., Moir, R., Wilson, A., Stones-Havas, S., Cheung, M., Sturrock, S., et al. 686 (2012). Geneious Basic: an integrated and extendable desktop software 687 platform for the organization and analysis of sequence data. Bioinformatics $688 \quad 28: 1647-1649$.

689 Kung, V.L., Ozer, E.A. and Hauser, A.R. (2010) The accessory genome of $690 \quad$ Pseudomonas aeruginosa. Microbiol Mol Biol Rev 74: 621-641.

691 Lenski, R.E., Rose, M.R., Simpson, S.C. and Tadler, S.C. (1991) Long-term 692 experimental evolution in Escherichia coli. I. Adaptation and divergence 693 during 2,000 generations. Am Nat 138: 1315-1341.

694 Lilley, A.K., Bailey, M.J. (1997) Impact of plasmid pQBR103 acquisition and 695 carriage on the phytosphere fitness of Pseudomonas fluorescens SBW25: 696 burden and benefit. Appl Environ Microbiol 63: 1584-1587. 
697 Lovell, H.C., Mansfield, J.W., Godfrey, S.A.C., Jackson, R.W., Hancock, J.T. and

698 Arnold, D.L. (2009). Bacterial evolution by genomic island transfer occurs via 699 DNA transformation in planta. Curr Biol 19: 1586-1590.

700 Mazzaglia, A., Studholme, D.J., Taratufolo, M.C., Cai, R., Almeida, N.F., Goodman, T., 701 et al. (2012) Pseudomonas syringae pv. actinidiae (PSA) isolates from recent 702 bacterial canker of kiwifruit outbreaks belong to the same genetic lineage. $703 \quad$ PLoS One 7: e36518.

704 Mergeay, M., Monchy, S., Vallaeys, T., Auquier, V., Benotmane, A., Bertin, P., et al. 705 (2003) Ralstonia metallidurans, a bacterium specifically adapted to toxic 706 metals: towards a catalogue of metal-responsive genes. FEMS Microbiol Rev $707 \quad 27: 385-410$.

708 McCann, H.C., Rikkerink, E.H.A., Bertels, F., Fiers, M., Lu, A., Rees-George, J., et al. 709 (2013) Genomic analysis of the kiwifruit pathogen Pseudomonas syringae pv. 710 actinidiae provides insight into the origins of an emergent plant disease. PLoS $711 \quad$ Pathogens 9: e1003503.

712 McCann, H.C., Li, L., Liu, Y., Templeton, M.D., Colombi, E., Straub, C., et al. (2016)

713 The origin and evolution of a pandemic lineage of the kiwifruit pathogen $714 \quad$ Pseudomonas syringae pv. actinidiae. In review.

715 Mohd-Zain, Z., Turner, S.L., Cerdeno-Tarraga, A.M., Lilley, A.K., Inzana, T.J., 716 Duncan, A.J., et al. (2004) Transferable antibiotic resistance elements in 717 Haemophilus influenzae share a common evolutionary origin with a diverse 718 family of syntenic genomic islands. J Bacteriol, 186: 8114-8122.

719 Morgan, R.K. and Taylor, E. (2004) Copper accumulation in vineyard soils in New $720 \quad$ Zealand. Environ Sci 1:2, 139-167.

721 Nakajima, M., Goto, M. and Hibi, T. (2002) Similarity between copper resistance 
724 Neale, H. C., Laister, R., Payne, J., Preston, G., Jackson, R. W. and Arnold, D. L.

725 (2016) A low frequency persistent reservoir of a genomic island in a pathogen

726 population ensures island survival and improves pathogen fitness in a

727 susceptible host. Environ Microbiol Accepted Author Manuscript.

$728 \quad$ doi:10.1111/1462-2920.13482

729 Ochman, H., Lerat, E., Daubin, V. (2005) Examining bacterial species under the

730 specter of gene transfer and exchange. Proc Natl Acad Sci U S A 102 Suppl 1:

$731 \quad 6595-6599$.

732 Ochman, H., Lawrence, J.G. and Groisman, E.A. (2010) Lateral gene transfer and 733 the nature of bacterial innovation. Nature 405: 299-304.

734 Peters, S.E., Hobman, J.L., Strike, P. and Ritchie, D.A. (1991) Novel mercury

735 resistance determinants carried by IncJ plasmids pMERPH and R391. Mol Gen $736 \quad$ Genet 228: 294-299.

737 Pitman, A.R., Jackson, R.W., Mansfield, J.W., Kaitell, V., Thwaites, R., et al. (2005)

738 Exposure to host resistance mechanisms drives evolution of bacterial

739 virulence in plants. Curr Biol 15: 2230-2235.

740 Polz, M.F., Alm, E.J., and Hanage, W.P. (2013) Horizontal gene transfer and the

741 evolution of bacterial and archaeal population structure. Trends Genet 29:

$742 \quad 170-175$.

743 Quiroz, T.S., Nieto, P.A., Tobar, H.E., Salazar-Echegarai, F.J., Lizana, R.J., Quezada

744 C.P., et al. (2011) Excision of an unstable pathogenicity island in Salmonella

745 enterica serovar enteritidis is induced during infection of phagocytic cells.

$746 \quad$ PLoS ONE 6: e26031. 
Ramsay, J.P., Sullivan, J.T., Stuart, G.S., Lamont, I.L. and Ronson, C.W. (2006) Excision and transfer of the Mesorhizobium loti R7A symbiosis island requires an integrase IntS, a novel recombination directionality factor RdfS, and a putative relaxase RlxS. Mol Microbiol 62: 723-734.

Rauch, P.J.G. and De Vos, W.M. (1992) Characterization of the novel nisin-sucrose conjugative transposonTn5276 and its insertion in Lactococcus lactis. J Bacteriol 174: 1280-1287.

Ravatn, R., Studer, S., Springael, D., Zehnder, A.J.B. and Van Der Meer, J.R. (1998) Chromosomal integration,tandem amplification, and deamplification in Pseudomonas putida F1 of a 105-kilobase genetic element containing the chlorocathecol degradative genes from Pseudomonas sp. strain B13. J Bacteriol 180: 4360-4369.

Rees-George, J., Vanneste, J.L., Cornish, D.A., Pushparajah, I.P.S., Yu, J., Templeton, M.D. and Everett, K.R. (2010) Detection of Pseudomonas syringae pv. actinidiae using polymerase chain reaction (PCR) primers based on the 16S-23S rDNA intertranscribed spacer region and comparison with PCR primers based on other gene regions. Plant Pathol 59: 453-464.

Rensing, C. and Grass, G. (2003) Escherichia coli mechanisms of copper homeostasis in a changing environment. FEMS Microbiol Rev 27: 197-213. Roberts, A.P. and Mullany, P. (2009) A modular master on the move: the Tn916 family of mobile genetic elements. Trends Microbiol 17: 251-258.

Ruinelli, M., Schneeberger, P.H.H., Ferrante, P., Bühlmann, A., Scortichini, M., Vanneste, J.L., et al. (2016) Comparative genomics-informed design of two LAMP assays for detection of the kiwifruit pathogen Pseudomonas syringae pv. actinidiae and discrimination of isolates belonging to the pandemic biovar 3 . 
772

773

Plant Pathol doi:10.1111/ppa.12551.

Staehlin, B.M., Gibbons, J.G., Rokas, A., O’Halloran, T.V. and Slot, J.C. (2016) Evolution of a heavy metal homeostasis/resistance island reflects increasing copper stress in Enterobacteria. Genome Biol Evol 8: 811-826.

Stoesser, N., Giess, A., Batty, E.M., Sheppard, A.E., Walker, A.S., Wilson, D.J., et al. (2014) Genome sequencing of an extended series of NDM-producing Klebsiella pneumoniae isolates from neonatal infections in a Nepali hospital characterizes the extent of community- versus hospital-associated transmission in an endemic setting. Antimicrob Agents Chemother 58: 73477357.

Sullivan, J.T., Patrick, H.N., Lowther, W.L., Scott, D.B. and Ronson, C.W. (1995) Nodulating strains of Rhizobium loti arise through chromosomal symbiotic gene transfer in the environment. Proc Natl Acad Sci USA 92: 8985-8989.

Sullivan, J.T. and Ronson, C.W. (1998) Evolution of rhizobia by acquisition of a 500-kb symbiosis island that integrates into a phe-tRNA gene. Proc Natl Acad Sci USA 95: 5145-514.

Templeton, M.D., Warren, B.A., Andersen, M.T., Rikkerink, E.H.A., Fineran, P.C. (2015) Complete DNA sequence of Pseudomonas syringae pv. actinidiae, the causal agent of kiwifruit canker disease. Genome Announc 3: e01054-15.

Teverson, D.M. (1991) Genetics of pathogenicity and resistance in the halo-blight disease of beans in Africa. Ph.D. thesis. University of Birmingham, Birmingham, United Kingdom.

Vanga, B.R., Ramakrishnan, P., Butler, R.C., Toth, I.K., Ronson, C.W., Jacobs, J.M.E. and Pitman, A.R. (2015) Mobilization of horizontally acquired island 2 is induced in plantain the phytopathogen Pectobacterium atrosepticum 
797 SCRI1043 and involves the putative relaxase ECA0613 and quorum sensing.

$798 \quad$ Environ Microbiol 17: 4730-4744.

799 Vanneste, J.L., Giovanardi, D., Yu, J., Cornish, D.A., Kay, C., Spinelli, F. and Stefani,

800 E. (2011) Detection of Pseudomonas syringae pv. actinidiae in kiwifruit pollen $801 \quad$ samples. N Z Plant Protect 64: 246-251.

802 Visnovsky, S.B., Fiers, M., Lu, A., Panda, P., Taylor, R. and Pitman, A.R. (2016)

803 Draft genome sequences of 18 strains of Pseudomonas isolated from kiwifruit 804 plants in New Zealand and overseas. Genome Announc 4: e00061-16.

805 Wozniak, R.A.F. and Waldor, M.K. (2010) Integrative and conjugative elements:

806 mosaic mobile genetic elements enabling dynamic lateral gene flow. Nat Rev

$807 \quad$ Microbiol 8: 552-563.

808 Zhang, X.X., Gauntlett, J.C., Oldenburg, D.G., Cook, G.M. and Rainey, P.B. (2015)

809 role of the transporter-like sensor kinase CbrA in histidine uptake and signal

$810 \quad$ transduction. J Bacteriol 197: 2867-2878.

811 Zhang, X.X., George, A., Bailey, M.J. and Rainey, P.B. (2006) The histidine

812 utilization (hut) genes of Pseudomonas fluorescens SBW25 are active on plant

813 surfaces, but are not required for competitive colonization of sugar beet

$814 \quad$ seedlings. Microbiol 152: 1867-1875.

815 


\section{TABLE AND FIGURE}

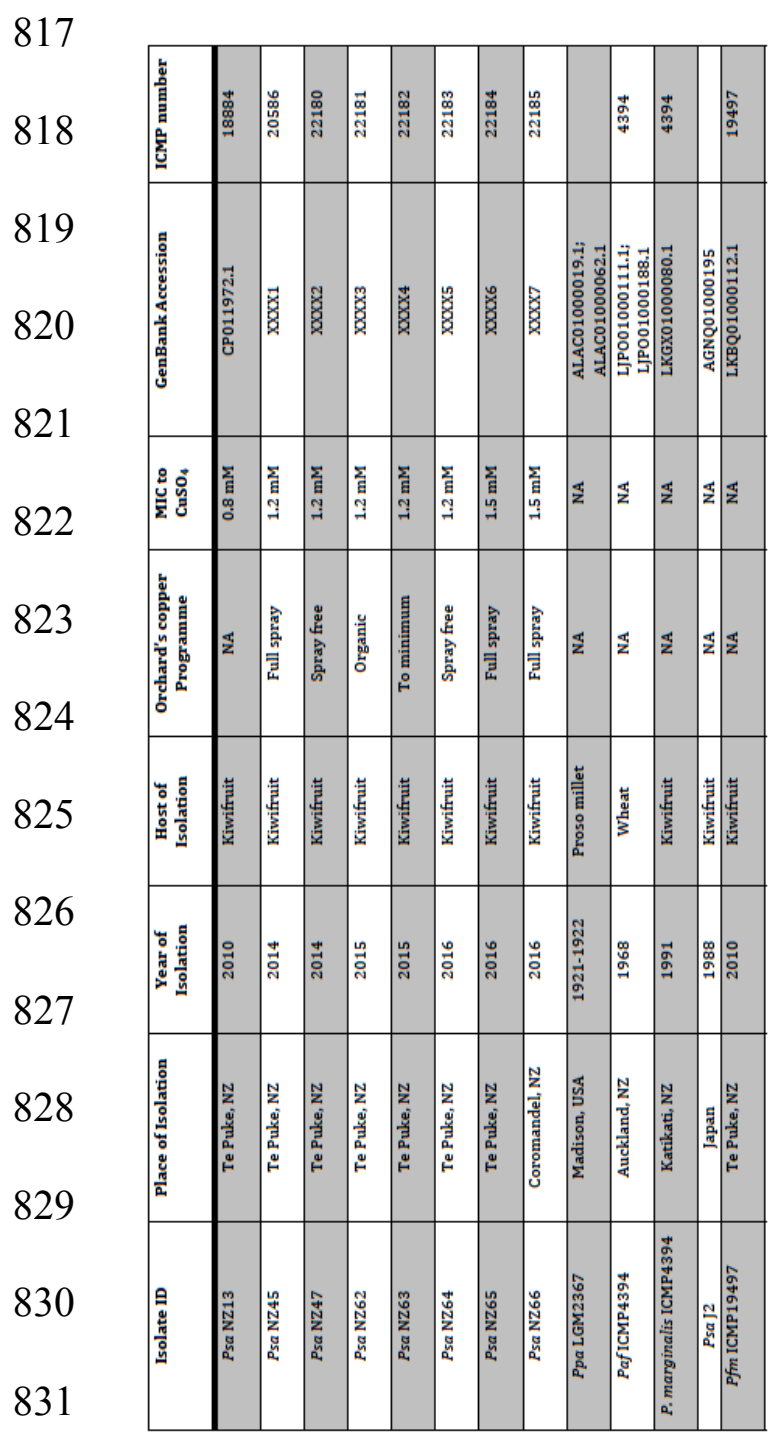

832 Table 1. List of genomes used in this study.

833 


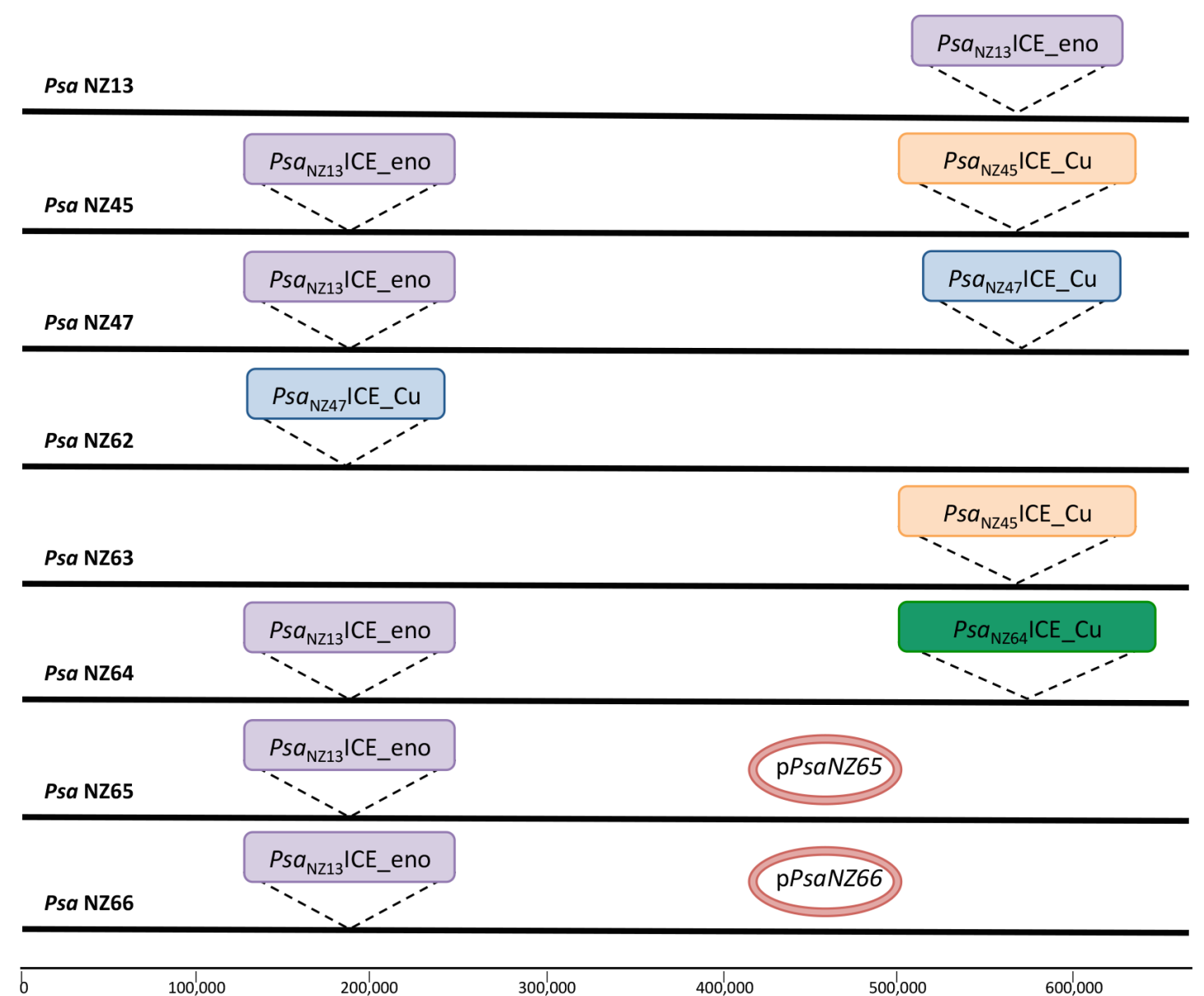

835 Figure 1. Genomic location of PsaICEs in Psa NZ13. In purple the

$836 P s a_{\text {NZ13 }} I C E_{-}$eno $(100 \mathrm{~kb})$, in orange $P s a_{\text {NZ45 }} \mathrm{ICE} \_\mathrm{Cu}(107 \mathrm{~kb})$, in blue the

$837 P s a_{\text {NZ47 }}$ ICE_Cu $(90 \mathrm{~kb})$, in green the $P s a_{\text {NZ64 }}$ ICE_Cu $(130 \mathrm{~kb})$, pPsaNZ65 and

838 pPsaNZ66 plasmids are $111 \mathrm{~kb}$. Each island is bounded by $52 \mathrm{bp}$ att sequences

839 overlapping tRNALys. In Psa NZ13 the att-1 site is located at 5,534,632 bp, att-2

840 at $1,733,972 \mathrm{bp}$. The figure is not to scale (the entire genome of $6.7 \mathrm{Mbp}$ is

841 indicated a single black line). Both $P s a_{\text {NZ13 ICE_Eno and } P s a_{\text {NZ47 }} I C E \_C u}$ ICEs were

842 detected in Psa NZ47 by sequencing, but analysis of independent colonies from

843 the freezer stock show that Psanz13ICE_Eno is prone to loss. 
A)

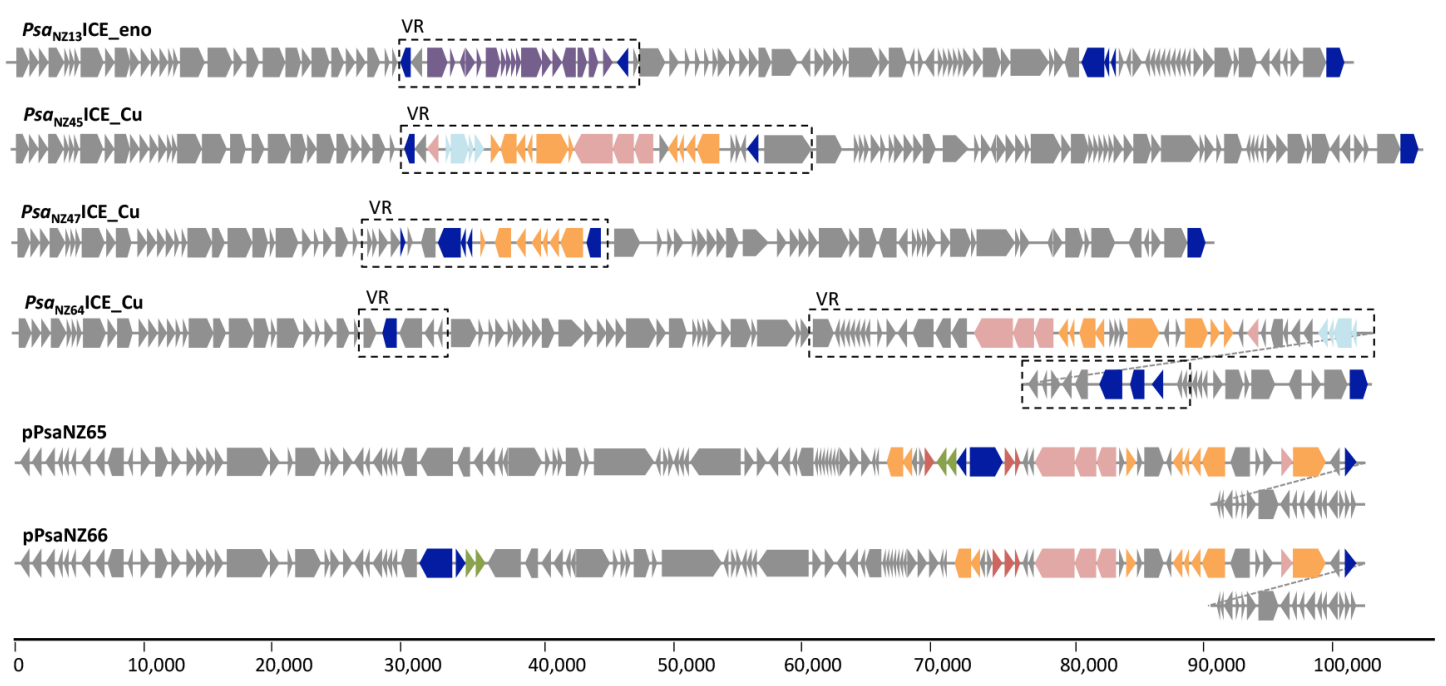

B)

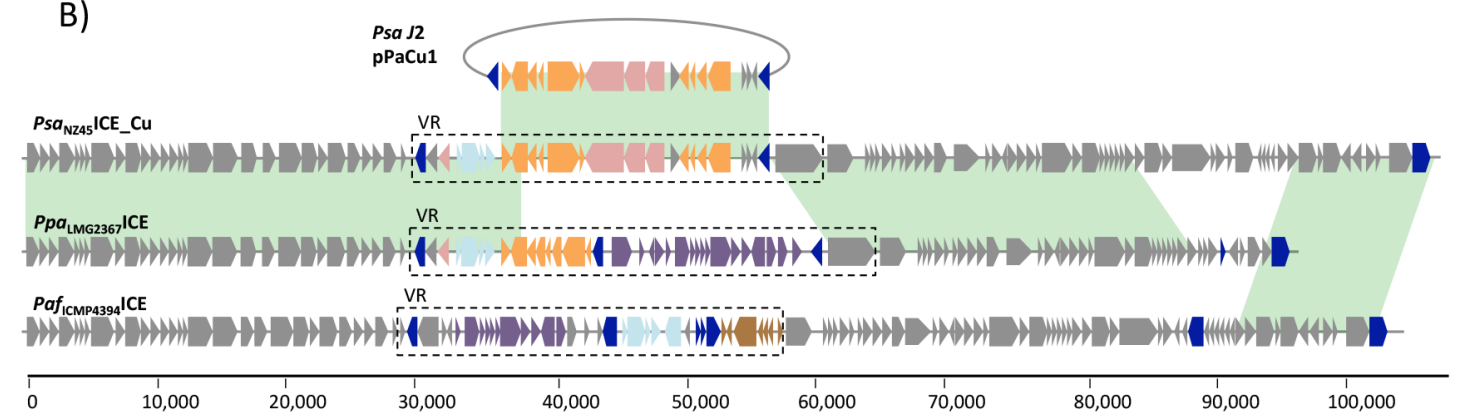

Figure 2. Genetic organization of ICEs and plasmids acquired by Psa and

848 A) Blue boxes are mobile genes (transposases or recombinases), purple boxes

849 define the 'enolase region', orange boxes depict copper resistance genes, azure

850 boxes are arsenic resistance genes, pink boxes are genes belonging to the $c z c / c u s$

851 system, green boxes are streptomycin resistance genes, red boxes are cation

852 transporter ATPases, brown boxes denote genes encoding mercury resistance.

853 Core "backbone" and other cargo genes are depicted as grey boxes. Dotted

854 diagonal lines indicate continuation of the element.

855 B) Areas in green show more than 99\% pairwise nucelotide identity.

$856 P s a_{\text {NZ45 }}$ ICE_Cu and $P p a_{\text {LGM2367 }}$ ICE share identity both in the first $38 \mathrm{~kb}$ and $20 \mathrm{~kb}$

857 downstream of VR. The remaining $20 \mathrm{~kb}$ of the $P s a_{\text {NZ45 }}$ ICE_Cu VR is almost 
858 identical to pPaCu1 (it differs by just 2 SNPs). The last $12.5 \mathrm{~kb}$ of $P_{s} a_{\text {NZ45 }} \mathrm{ICE}_{-} \mathrm{Cu}$ is

859 identical to $\mathrm{Paf}_{\mathrm{ICMP} 4394 \mathrm{ICE} .}$

860

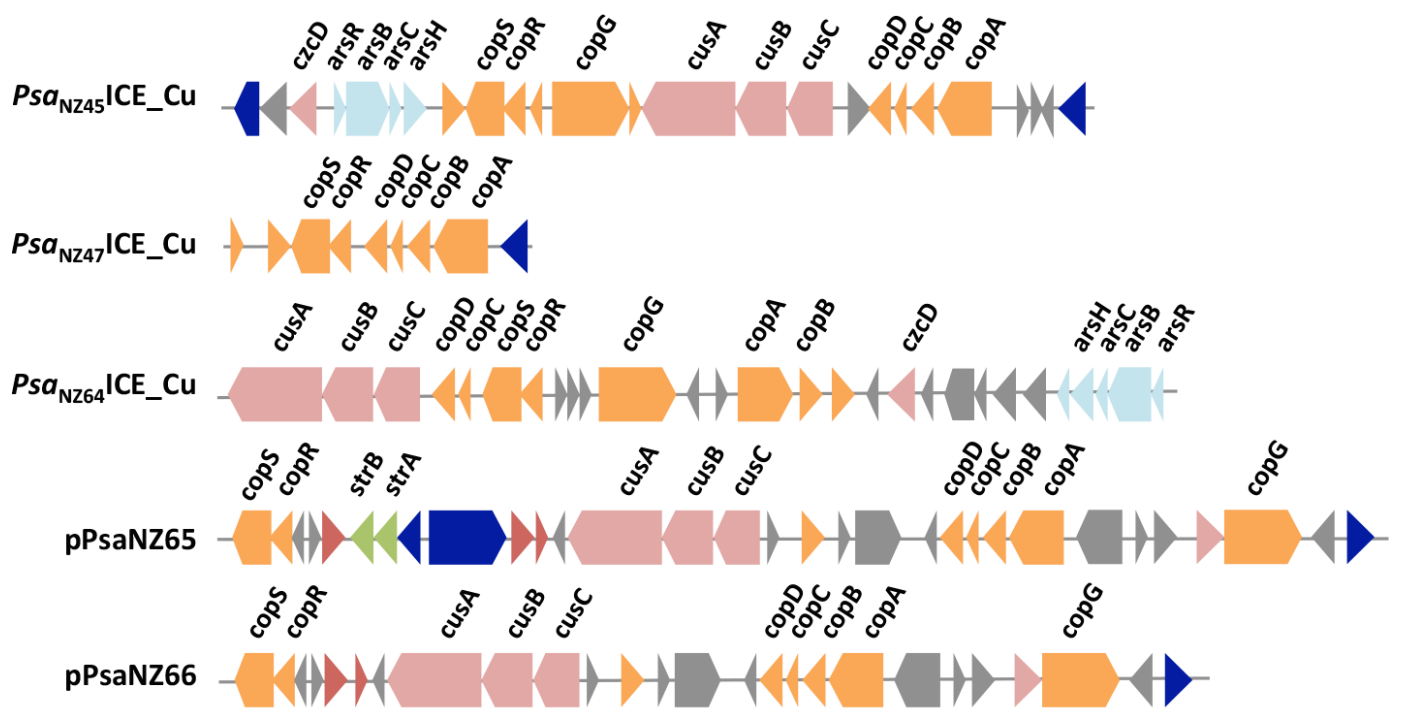

861

862

863 Figure 3. Genetic organization of metal resistance loci. Blue boxes are mobile

864 genes (transposases or recombinases), orange boxes depict copper resistance

865 genes, azure boxes are arsenic resistance genes, pink boxes are genes belonging

866 to the $c z c / c u s$ system, green boxes are streptomycin resistance genes and other

867 genes are depicted as grey boxes.

868 
869

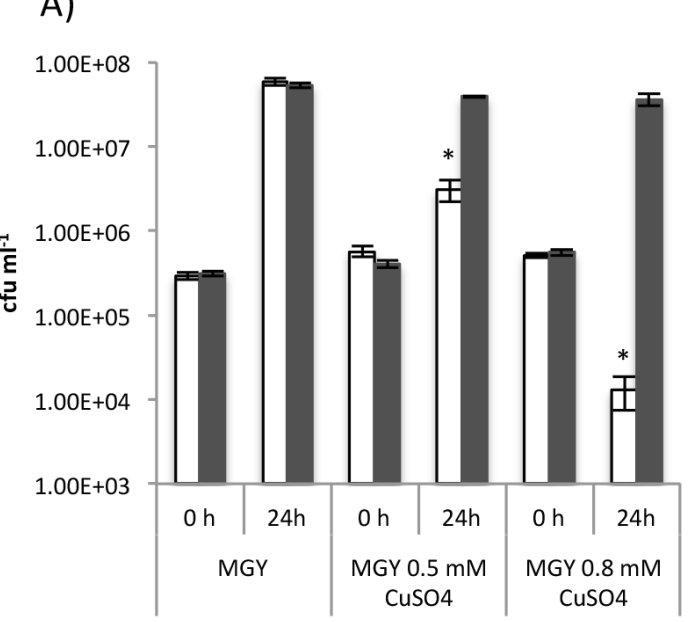

B)

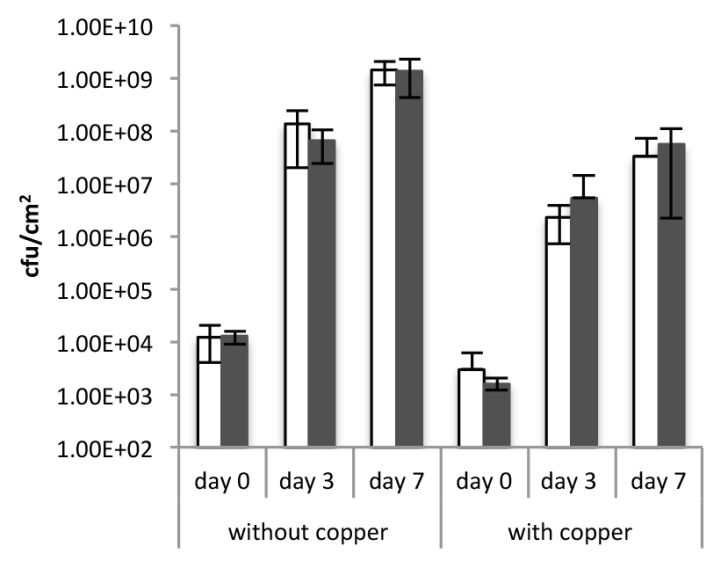

$870 \quad$ Figure 4. Effect of copper ions on growth of Psa NZ13 and Psa NZ45.

871 A) Psa NZ13 (white bars) and Psa NZ45 (grey bars) were grown for $24 \mathrm{~h}$ in

872 shaken MGY culture and MGY supplemented with $0.5 \mathrm{mM}$ and $0.8 \mathrm{mM} \mathrm{CuSO}_{4}$.

873 Data are means and standard deviation of three independent cultures. *indicates

874 significant difference $P<0.05$ (one tailed $t$-test)).

875 B) The single growth of Psa NZ13 (white bars) and Psa NZ45 (grey bars) was

876 assessed endophytically on leaves of the kiwifruit cultivar Hort16A. Data are

877 means and standard deviation of five replicates. The copper product Nordox75

$878\left(0.375 \mathrm{~g} \mathrm{~L}^{-1}\right)$ was sprayed adaxially and abaxially until run off. Data are means

879 and standard deviation of 5 replicates. One tailed $t$-test showed no statistical

880 difference in growth between of Psa NZ13 and NZ45 in absence or presence of

881 copper. 


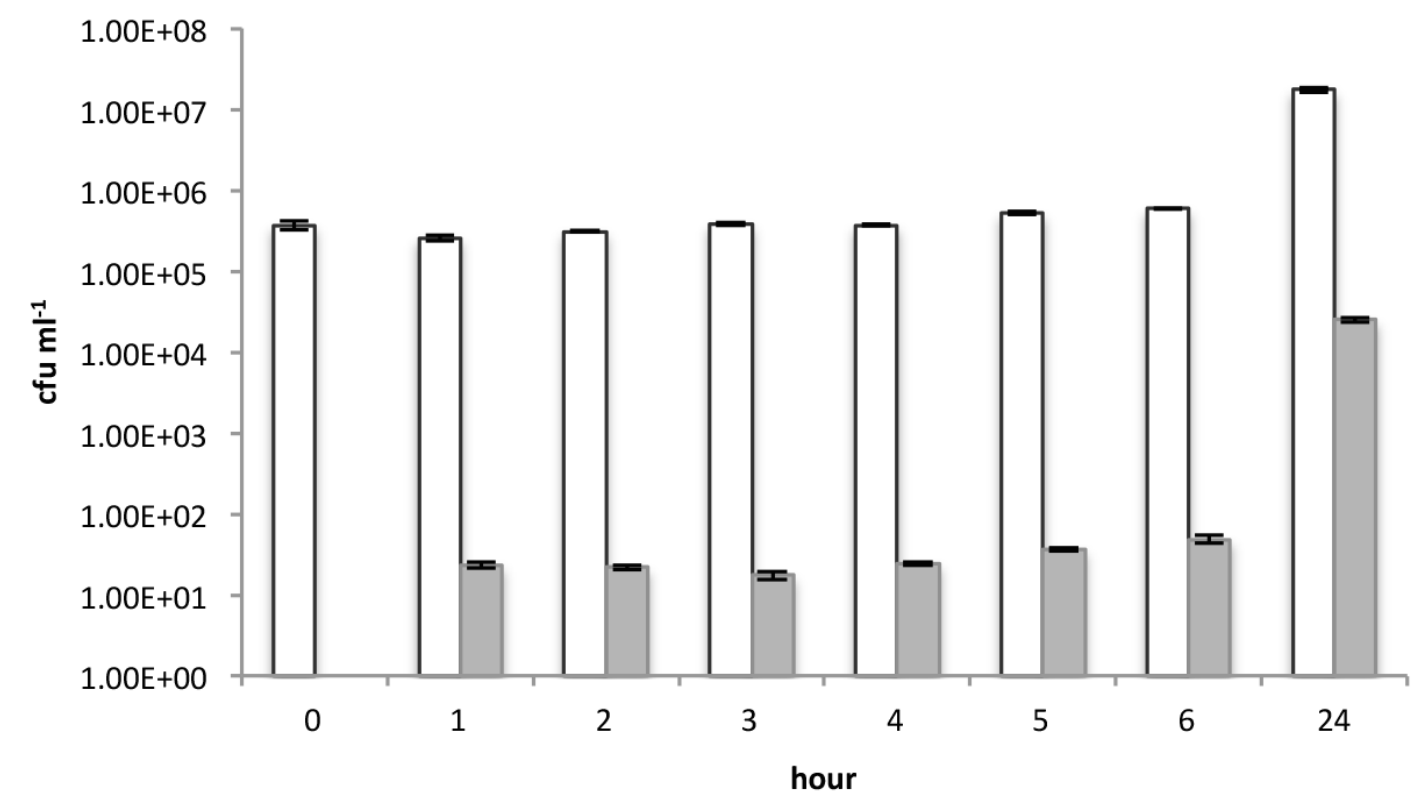

883

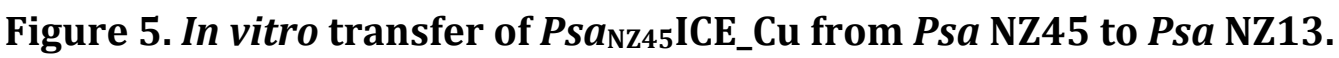

885 Colony forming units of the recipient Psa NZ13 (white bars) and Psa NZ13

886 carrying $P_{s} a_{\mathrm{NZ45}} \mathrm{ICE}_{-} \mathrm{Cu}$ (transconjugants, grey bars) was monitored during co-

887 cultivation. Data are means and standard deviation of 3 independent cultures 888 


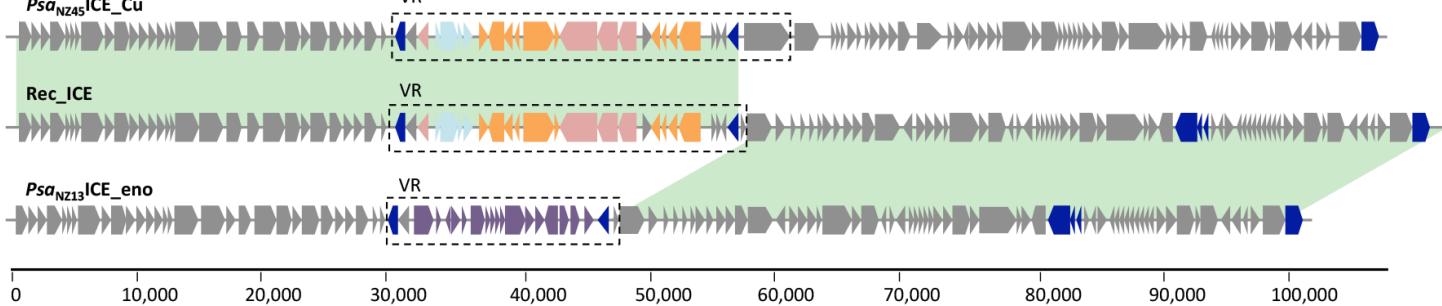

890 Figure 6. Structure and mosaicism of the recombinant ICE (Rec_ICE) in

891 transconjugant Psa NZ13. Areas highlighted in green show 100\% pairwise

892 identity. The recombination break point is inside the variable region (VR). Blue

893 boxes are mobile genes (transposases or recombinases), purple boxes define the

894 'enolase region' (McCann et al. 2013), orange boxes depict copper resistance

895 genes, azure boxes are arsenic resistance genes and pink boxes are genes

896 belonging to the $c z c / c u s$ system. Core "backbone" and other cargo genes are

897 depicted as grey boxes.

898

899

900

901

902

903

904

905

906

907

908

909 


\section{SUPPORTING INFORMATION}

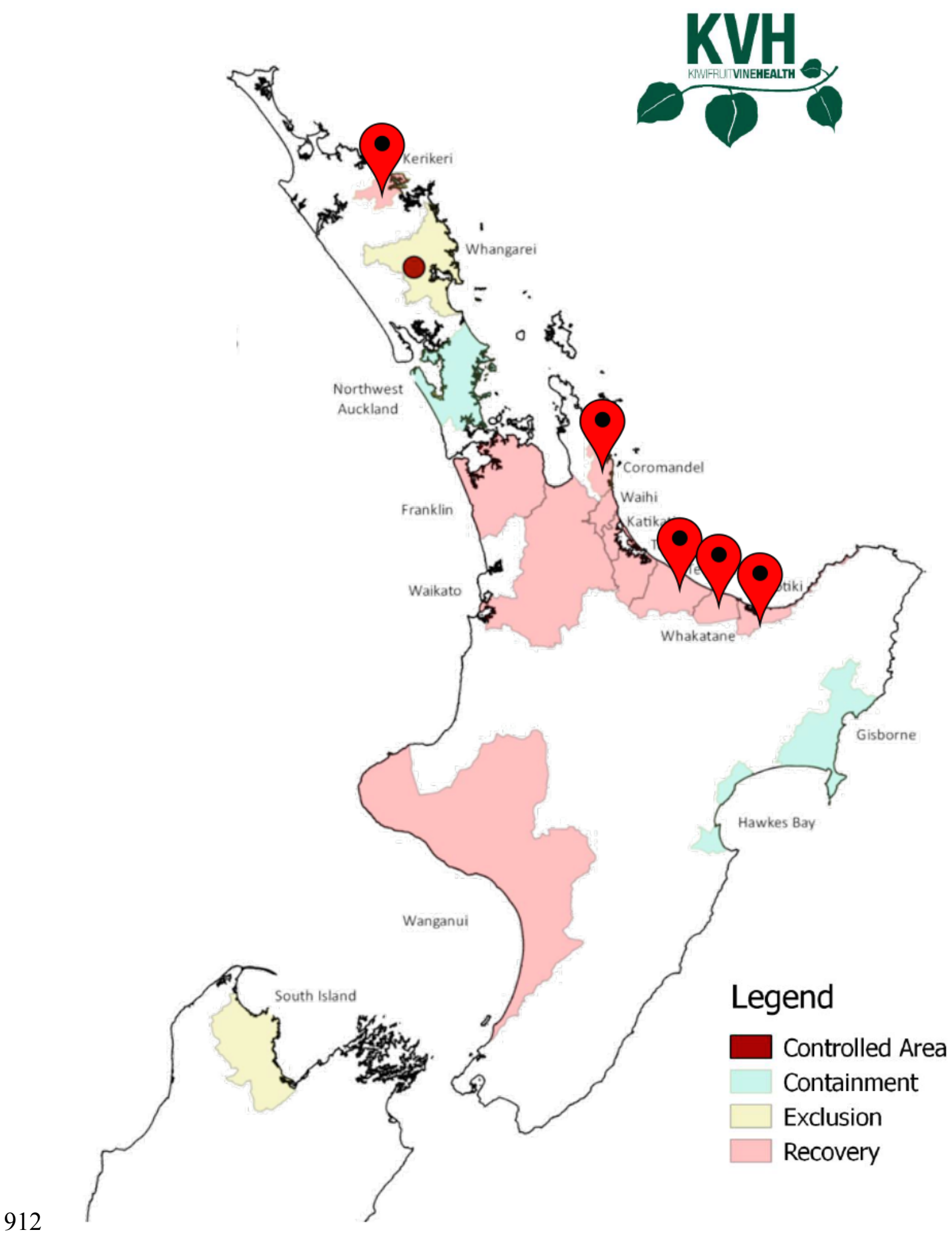

913 Figure S1 - New Zealand kiwifruit growing regions with isolation sites of copper

914 resistant Psa. Map was modified from regional classification map of June 2016

915 (Kiwi Vine Health (KVH)). 

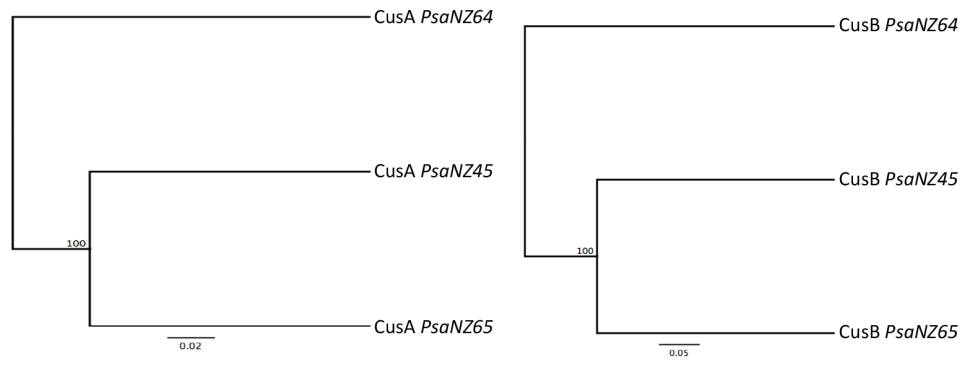

916

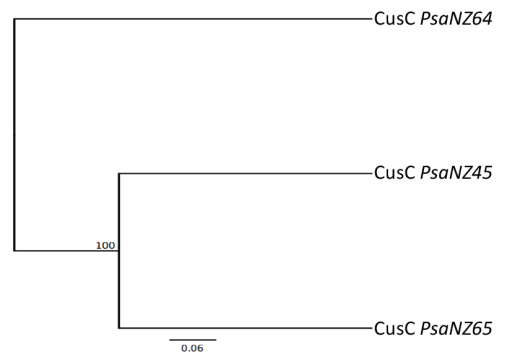

917 Figure S2 - UPMGA tree of the Cus system proteins in Psa NZ. Bootstrap

918 values are shown at each node.
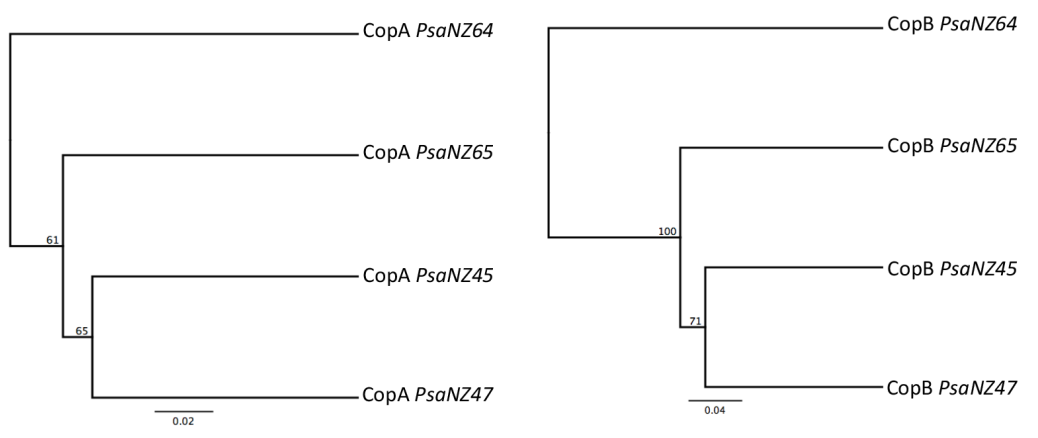

920 Figure S3 - UPMGA trees of the Cop proteins genes in Psa NZ. Bootstrap

921 values are shown at each node. 

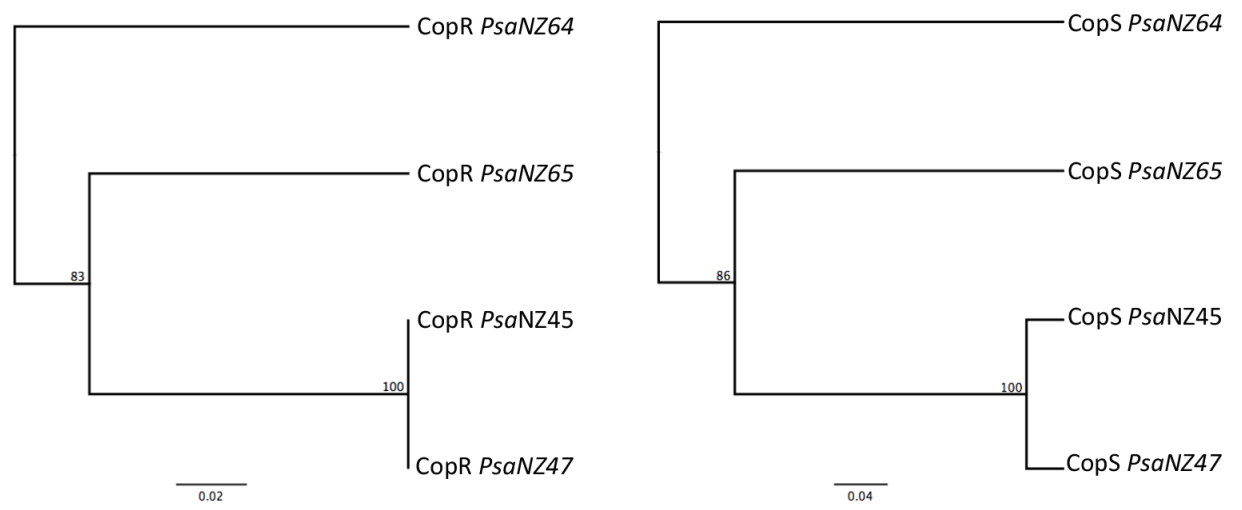

Figure S4 - UPMGA trees of CopR and CopS proteins in Psa NZ. Bootstrap

927 values are shown at each node.

928

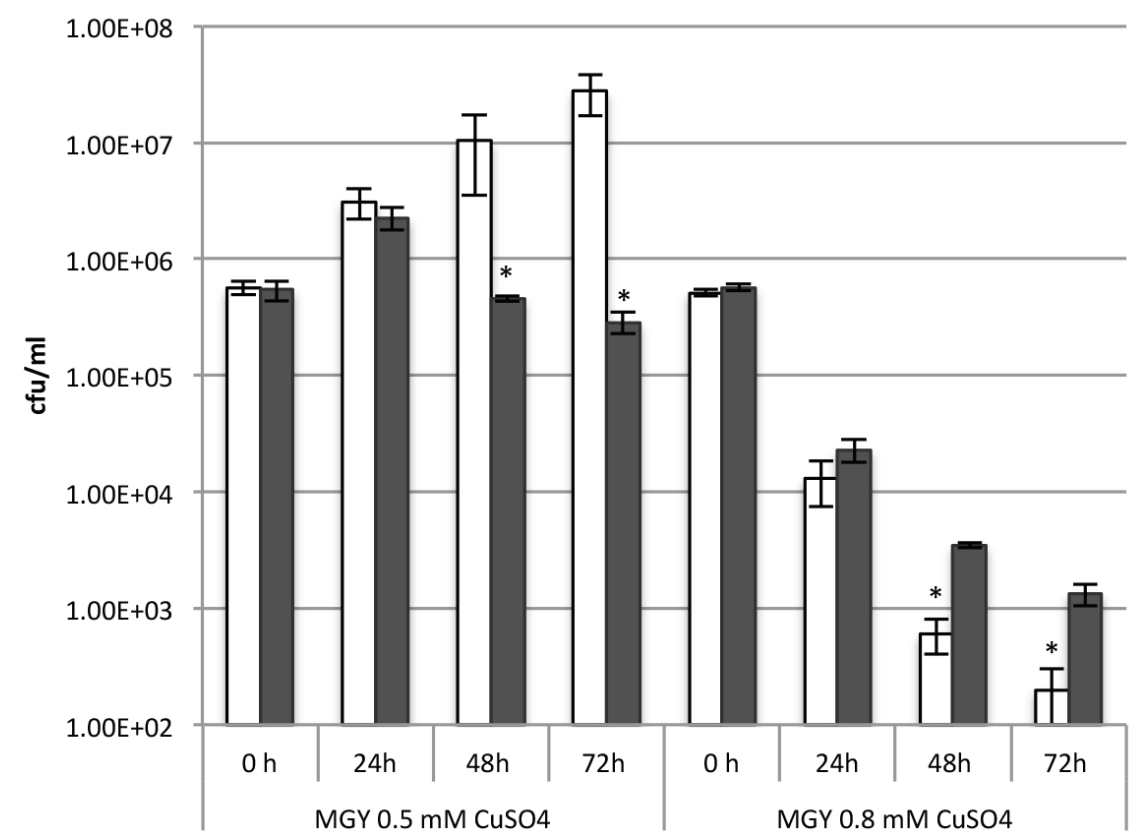

930 Figure S5. Density of single and co-cultured Psa in liquid MGY

931 supplemented with $\mathbf{0 . 5} \mathbf{~ m}$ and $0.8 \mathbf{m M ~ C u S O}_{4}$. Psa NZ13 was cultured alone

932 (white bars) or co-cultured with Psa NZ45 (grey bars). Data are means and

933 standard deviation of three independent cultures. *indicates significance at 5\%

934 level by one-tailed $t$-test. 


\begin{tabular}{|c|c|c|}
\hline & \multicolumn{2}{|c|}{ Frequency of Psa ${ }_{\text {NZ45 ICE_Cu transconjugants }}$ day 7 } \\
\hline Psa NZ13 $:$ Psa NZ45 & day 3 & $(2.28 \pm 0.7)^{-2}$ \\
\hline $1: 1$ & $(2.05 \pm 0.63)^{-2}$ & $(3.14 \pm 2.3)^{-2}$ \\
\hline $1: 0.1$ & $(1.34 \pm 0.52)^{-2}$ & $(1.88 \pm 0.81)^{-2}$ \\
\hline $0.1: 1$ & $(1.68 \pm 0.68)^{-2}$ & \\
\hline
\end{tabular}

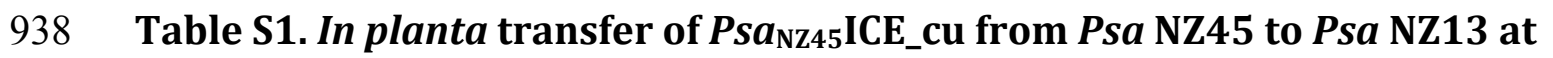

939 different founding ratios of donor and recipient. Donor and recipient strains

940 were dip-inoculated onto Hort16A leaves at different founding ratios and

941 frequency of recipients determined at days 3 and 7

\begin{tabular}{ll}
\hline Primer name & Sequence \\
\hline copA for & ATCCGCGGTGACTCGATAAC \\
\hline copA rev & CAGTCGATGGACCGTACTGG \\
\hline enolase for & GAGCTGACGTCCGACATAGAG \\
\hline enolase rev & CCAGTCCAACAGGTTTACCG \\
\hline IntPsanZ13 & GTCAGGCTGATCACTTACGTTG \\
\hline IntPsanZ45 & GTCAGGCTGATCACTAGCGTTA \\
\hline att-1 & TGTAGAATAGCGCGCCTCAG \\
\hline att-2 & AGCCGTAATCCTGCTGTCC \\
\hline
\end{tabular}

943 Table S2. Primers used for $P s a_{\text {NZ13 }}$ ICE_eno and Psa ${ }_{\text {NZ45 ICE_Cu detection and }}$ 944 integration loci. 


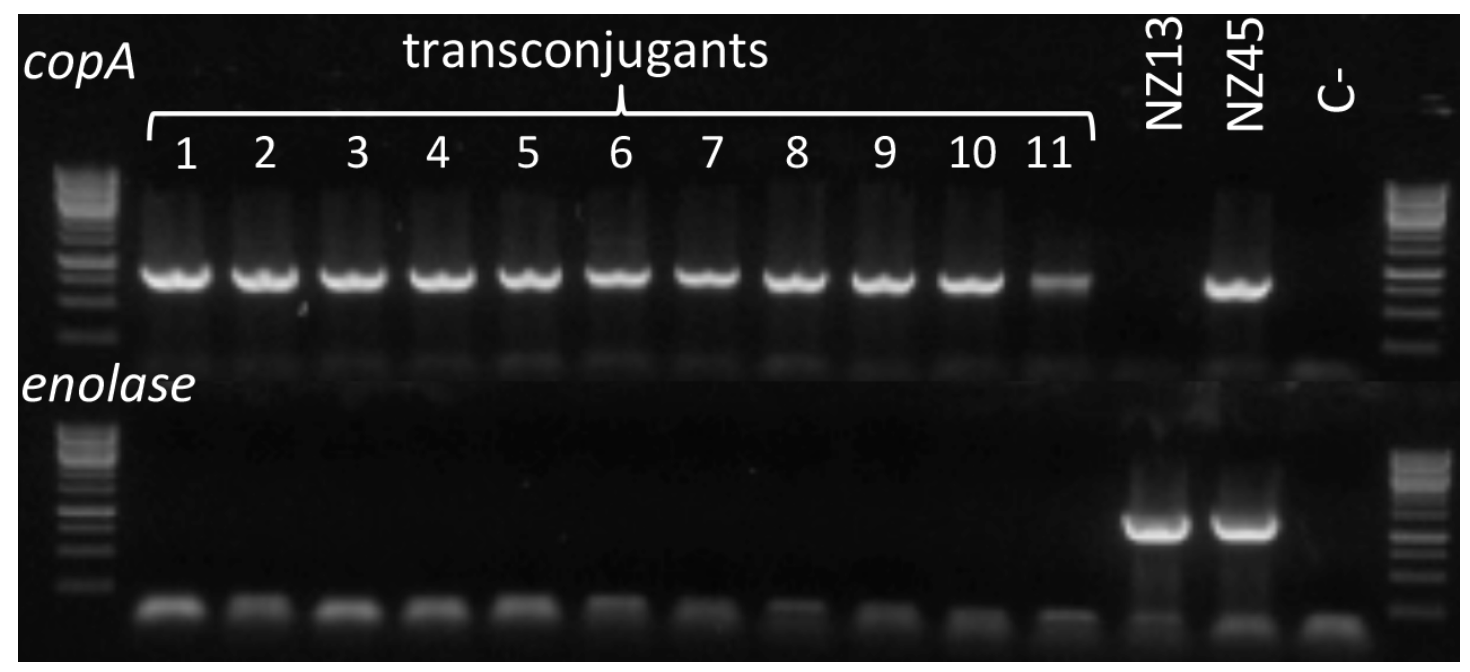

946

947 Figure S6. Analysis of the presence of the variable region (VR) of

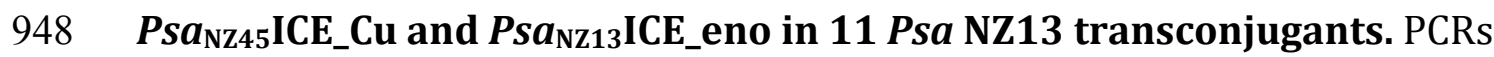

949 were carried out to detect $\operatorname{copA}$ (VR of $P s a_{\mathrm{NZ45}} \mathrm{ICE} \_\mathrm{Cu}$ ) or enolase genes (VR of

$950 \quad P s a_{\text {NZ13 }}$ ICE_eno). Controls of Psa NZ13 and Psa NZ45 show one and two bands,

951 indiciative of $P s a_{\mathrm{NZ13}} \mathrm{ICE}$ _eno in $P s a$ NZ13 and both $P s a_{\mathrm{NZ13}} \mathrm{ICE}_{-}$eno $P s a_{\mathrm{NZ45}} \mathrm{ICE} \_\mathrm{Cu}$

952 and in Psa NZ45, respectively. All transconjugants, lanes 1-11 have acquired

$953 P s a_{\mathrm{NZ45}} \mathrm{ICE} \mathrm{C} \mathrm{Cu}$.

954

955

956

957

958

959

960

961

962 


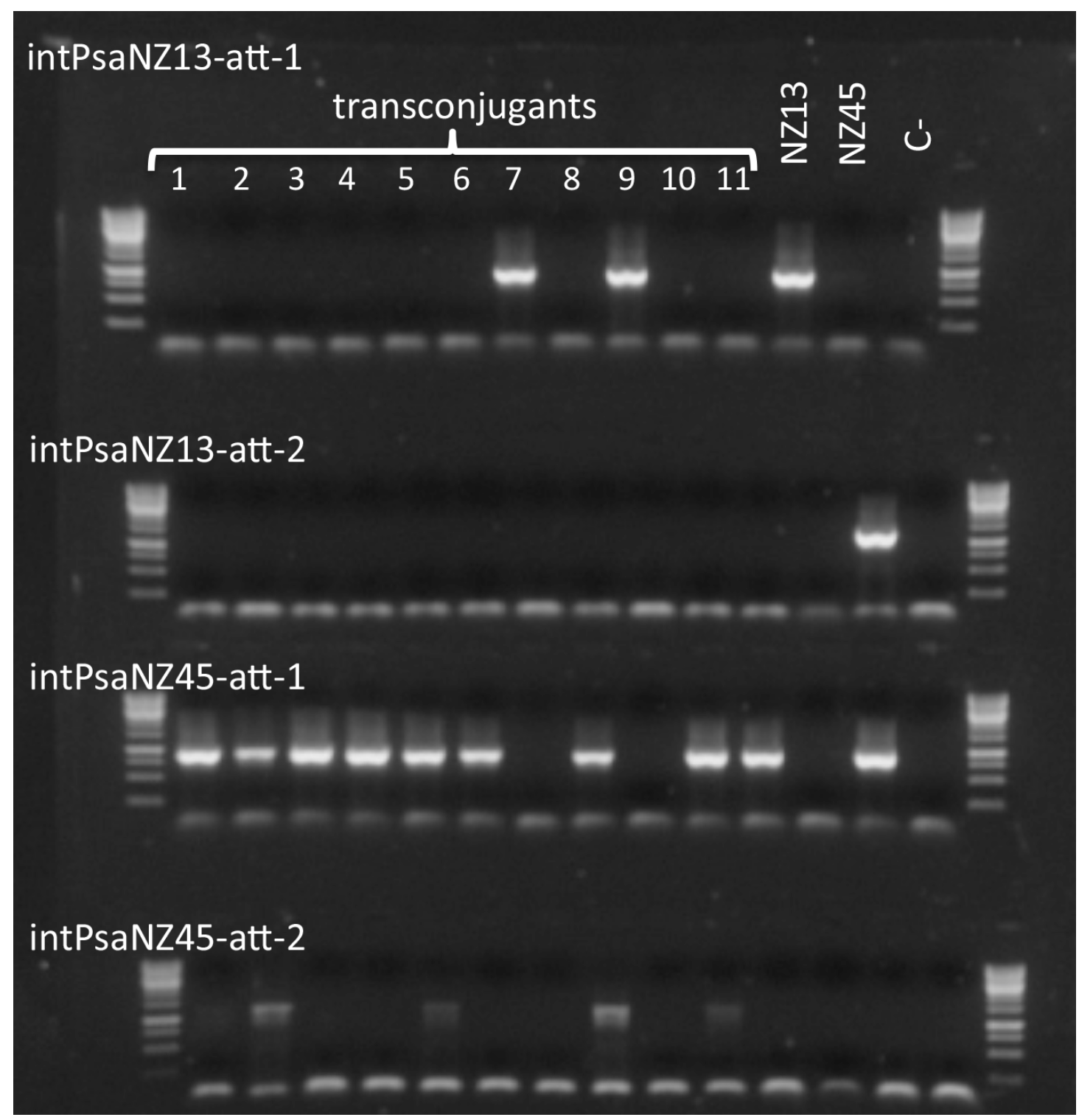

\section{Figure $\mathbf{S 7}$. Analysis of the insertion site of the Psa ${ }_{\text {NZ13 }}$ ICE_eno and}

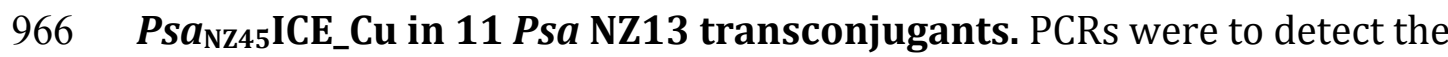

967 integration of $P s a_{\mathrm{NZ13}}$ ICE_eno in the att-1 or att-2 sites (intPsaNZ13-att-1 and

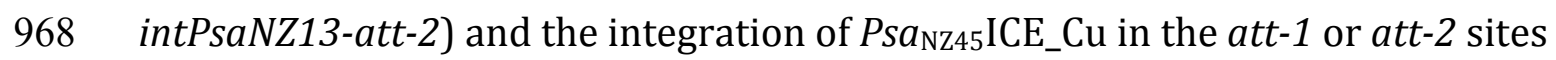

969 (intPsaNZ45-att-1 and intPsaNZ45-att-2). Controls of Psa NZ13 and Psa NZ45

970 show that in Psa NZ13 the $P s a_{\text {NZ13 }}$ ICE_eno is integrated in the att-1 site and in

$971 P s a$ NZ45 the Psa ${ }_{\text {NZ13 }}$ ICE_eno is integrated in the att-1 and the Psa $a_{\mathrm{NZ45}} \mathrm{ICE}$ _Cu in

972 the att-2 site. 